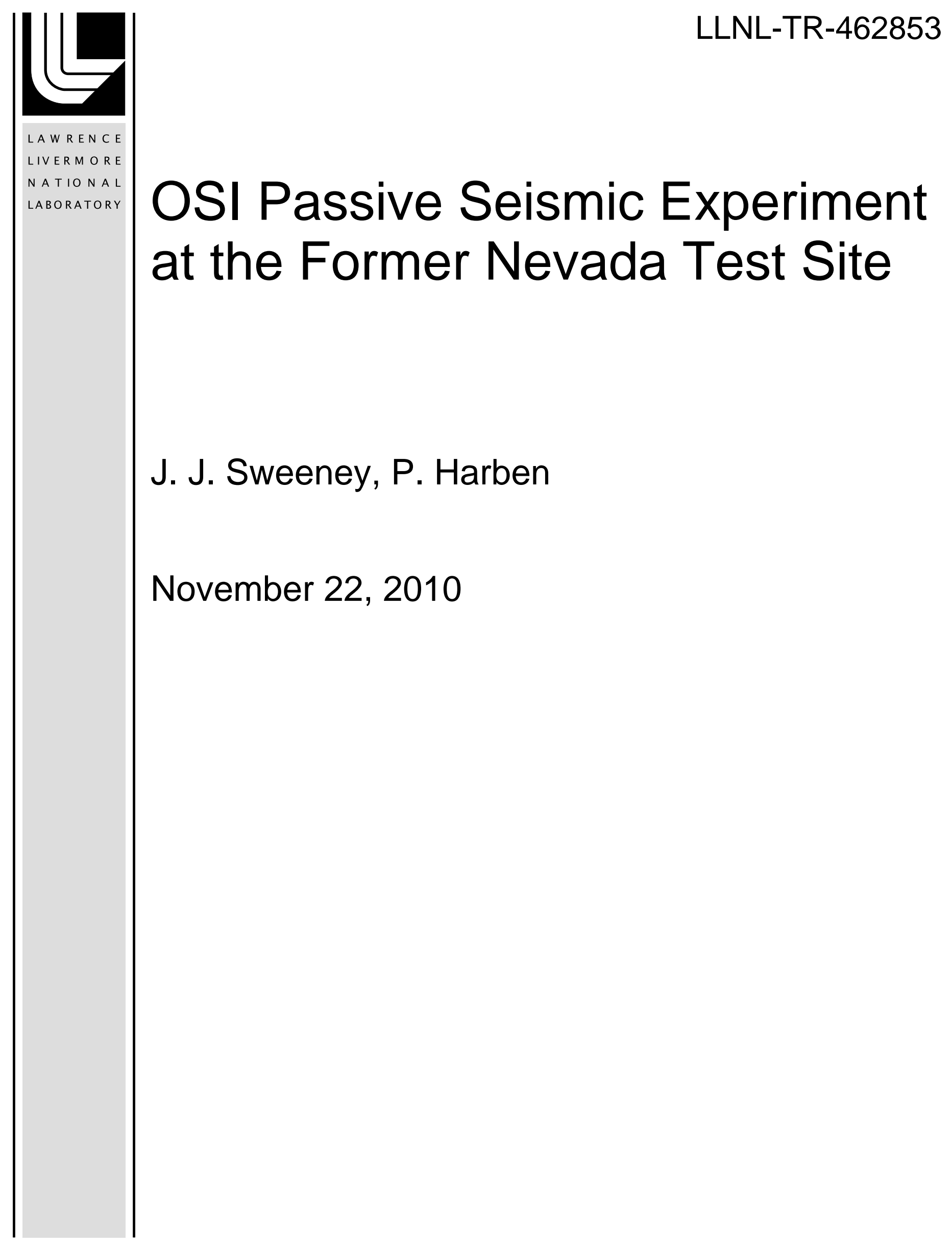


This document was prepared as an account of work sponsored by an agency of the United States government. Neither the United States government nor Lawrence Livermore National Security, LLC, nor any of their employees makes any warranty, expressed or implied, or assumes any legal liability or responsibility for the accuracy, completeness, or usefulness of any information, apparatus, product, or process disclosed, or represents that its use would not infringe privately owned rights. Reference herein to any specific commercial product, process, or service by trade name, trademark, manufacturer, or otherwise does not necessarily constitute or imply its endorsement, recommendation, or favoring by the United States government or Lawrence Livermore National Security, LLC. The views and opinions of authors expressed herein do not necessarily state or reflect those of the United States government or Lawrence Livermore National Security, LLC, and shall not be used for advertising or product endorsement purposes.

This work performed under the auspices of the U.S. Department of Energy by Lawrence Livermore National Laboratory under Contract DE-AC52-07NA27344. 


\section{OSI Passive Seismic Experiment at the former Nevada Test Site}

\section{Introduction}

On-site inspection (OSI) is one of the four verification provisions of the Comprehensive Nuclear Test Ban Treaty (CTBT). Under the provisions of the CTBT, once the Treaty has entered into force, any signatory party can request an on-site inspection, which can then be carried out after approval (by majority voting) of the Executive Council. Once an OSI is approved, a team of 40 inspectors will be assembled to carry out an inspection to "...clarify whether a nuclear weapon test explosion or any other nuclear explosion has been carried out in violation of Article I...". One challenging aspect of carrying out an on-site inspection (OSI) in the case of a purported underground nuclear explosion is to detect and locate the underground effects of an explosion, which may include an explosion cavity, a zone of damaged rock, and/or a rubble zone associated with an underground collapsed cavity. The CTBT (Protocol, Section II part D, paragraph 69) prescribes several types of geophysical investigations that can be carried out for this purpose.

One of the methods allowed by the CTBT for geophysical investigation is referred to in the Treaty Protocol as "resonance seismometry". This method, which was proposed and strongly promoted by Russia during the Treaty negotiations, is not described in the Treaty. Some clarification about the nature of the resonance method can be gained from OSI workshop presentations by Russian experts in the late 1990s. Our understanding is that resonance seismometry is a passive method that relies on seismic reverberations set up in an underground cavity by the passage of waves from regional and teleseismic sources. Only a few examples of the use of this method for detection of underground cavities have been presented, and those were done in cases where the existence and precise location of an underground cavity was known. As is the case with many of the geophysical methods allowed during an OSI under the Treaty, how resonance seismology really works and its effectiveness for OSI purposes has yet to be determined.

For this experiment, we took a broad approach to the definition of "resonance seismometry"; stretching it to include any means that employs passive seismic methods to infer the character of underground materials. In recent years there have been a number of advances in the use of correlation and noise analysis methods in seismology to obtain information about the subsurface. Our objective in this experiment was to use noise analysis and correlation analysis to evaluate these techniques for detecting and characterizing the underground damage zone from a nuclear explosion. The site that was chosen for the experiment was the Mackerel test in Area 4 of the former Nevada Test Site (now named the Nevada National Security Site, or NNSS). Mackerel was an underground nuclear test of less than 20 kT conducted in February of 1964 (DOENV-209-REV 15). The reason we chose this site is because there was a known apical cavity occurring at about $50 \mathrm{~m}$ depth above a rubble zone, and that the site had been investigated by the US Geological Survey with active seismic methods in 1965 (Watkins et al., 1967). Note that the time delay 
between detonation of the explosion (1964) and the time of the present survey (2010) is nearly 46 years - this would not be typical of an expected OSI under the CTBT.

\section{Experiment plan and objective:}

The objective of the experiment was to determine whether there are any consistent differences is seismic recordings near or over an underground nuclear test zone (Mackerel event in borehole U4a) compared to recordings over an undisturbed subsurface. For this purpose two lines of seismometers were installed. Line A was designed to traverse the underground damage zone as much as possible and extend out beyond where underground damage would be expected; line B was intended to be a control line, with the same spacing between seismometers, but this line would not have a damage zone beneath (or near) it. Unfortunately, for safety reasons, there is a no-entry zone marked around U4a (because of potential surface collapse) so we were not able to run line A directly over explosion ground zero; we ran the line right next to the exclusion fence as is seen by the semi-circular diversion in the map below. The map below shows ground zero of the shot (white arrow), line A going near the shot zone, and line B parallel and offset from line A to serve as a reference over an undisturbed subsurface. The station spacing is nominally 50 meters and the lines trend east-west. The seismometers were deployed for a period of about six weeks, collecting continuous data. Data were downloaded from the digitizers every two weeks.

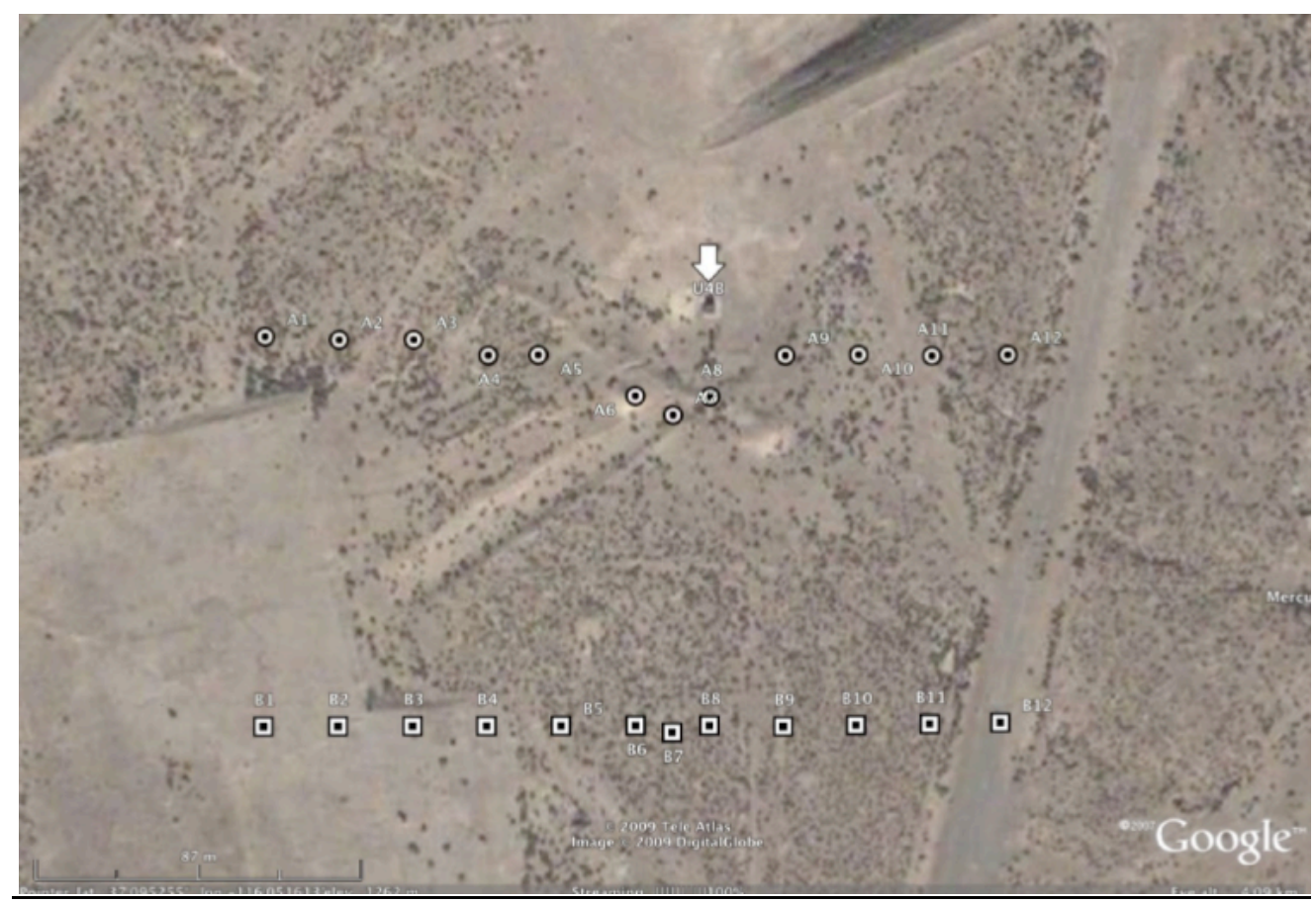

Map showing locations of vertical seismometers (squares) emplaced for the passive seismic experiment. Spacing is about 50 meters. The southern control line (line B) is located $150 \mathrm{~m}$ south of line A. The white arrow marks ground zero of event U4a. 


\section{Approach:}

Three distinct analysis approaches are presented below. The first uses the continuous seismic data to create power density spectra each hour for the full archive at each station. From the collection of spectra, statistical noise models are created for each station and compared in a number of ways to see if consistent differences over the underground damage zone can be discerned.

The second method uses cross-correlation methods, such as coherence, to compare the noise fields at adjacent and other stations. The approach uses the background noise data to discern if there is a consistent breakdown of coherence over the shot zone.

The third method evaluates three specific events that span an azimuth variation of arrivals of waves that would pass through the damage zone before arriving at the seismometers. The event waveforms from each station are compared to see if consistent differences in features can be discerned for the stations over the shot zone at some or all event azimuths. The event waveforms are also compared to a reference station using a moving window cross correlation method.

\section{Sensor, Recorder, and Data Specifics:}

The data utilized for the series of analyses below consist of 39 days of data taken in November/December, 2009. The data is continuous, 24-bit, 100 samples per second, recorded on a Reftek digitizer. The sensors are Geotech GS-13 vertical component short period seismometers. The nominal generator constant for the GS-13 is 2180 $\mathrm{V} / \mathrm{m} / \mathrm{sec}$ with a low frequency corner of $1 \mathrm{~Hz}$.

Although data had been collected over a much longer period, the analysis is focused on the final days of the deployment when the data quality is known to be good. That said, there was a problem with one of the recorders on the line $B$ that makes that data unusable (recorder 9DB2, stations B7 to B12 at the western end of the line). Consequently, only half of the stations for line B (B1 to B6) are utilized, although all of line A stations are used (A1-A12). 


\section{Noise Model Analysis:}

The calculation procedure for the spectra and noise models are described in the Appendix. Noise models were calculated for the 39 days of data with the following spectra count for each station (i.e. the number of spectra that make up the noise model and that are in the SPECS directory for that station).

\begin{tabular}{|l|l|l|l|l|l|l|l|l|l|l|l|l|}
\hline STA & A1 & A2 & A3 & A4 & A5 & A6 & A7 & A8 & A9 & A10 & A11 & A12 \\
\hline NUM & 927 & 923 & 922 & 923 & 925 & 916 & 915 & 904 & 921 & 917 & 927 & 920 \\
\hline
\end{tabular}

\begin{tabular}{|l|l|l|l|l|l|l|}
\hline STA & B1 & B2 & B3 & B4 & B5 & B6 \\
\hline NUM & 915 & 909 & 883 & 905 & 921 & 915 \\
\hline
\end{tabular}

The noise models for all stations are shown in the panels of contour plots below. Each panel shows the frequency in $\mathrm{Hz}$ (horizontal) versus the cumulative number of counts for a particular noise level (vertical). The color contours denote the noise power for the number of counts, with "hotter" colors for the highest noise power. Note that, for clarity in showing the contours of noise power, the peak intensity associated with a given color contour is not the same from one panel to the next, so variation in color levels does not necessarily indicate a difference in peak noise power at a given frequency (refer to the plots of noise power versus number of counts for a given frequency that are shown after the ones below). 
A1

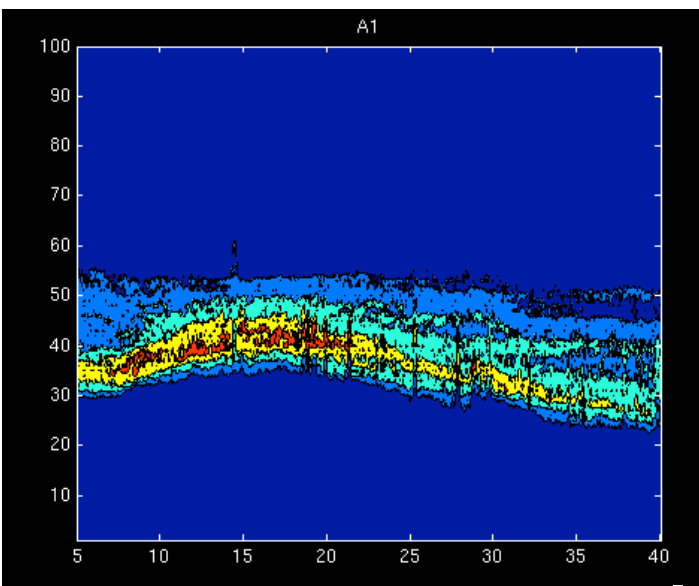

A3

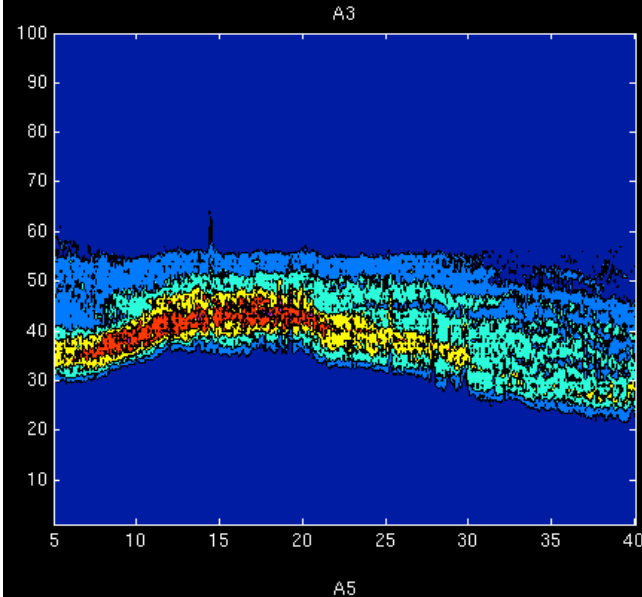

A5

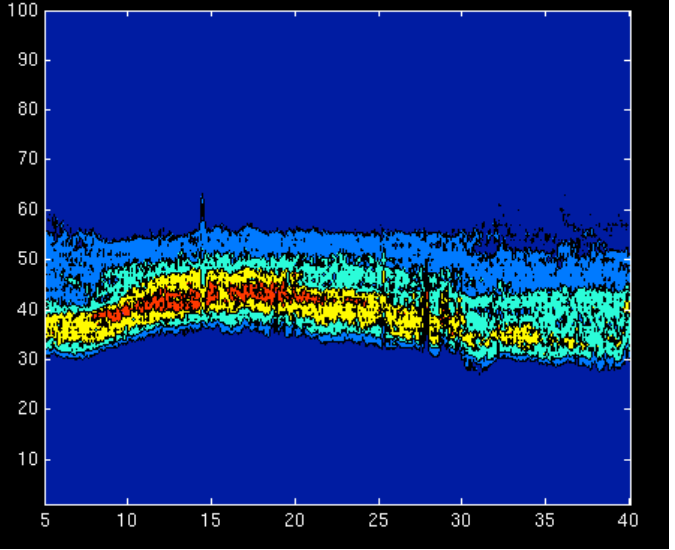

A2

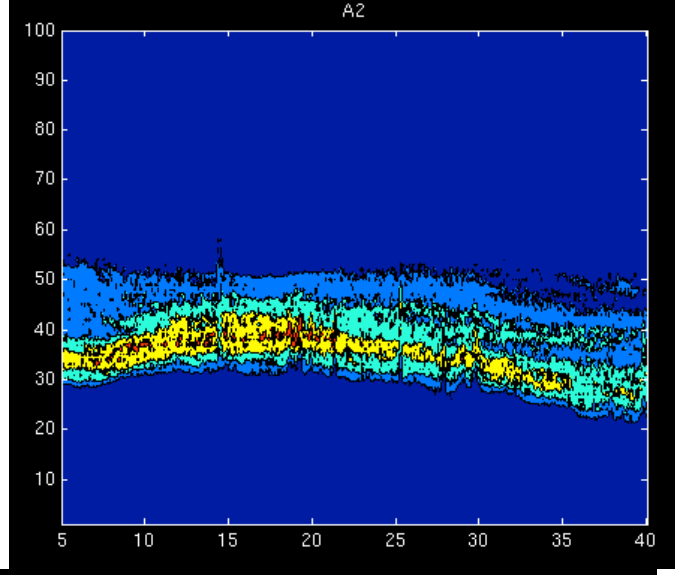

A4

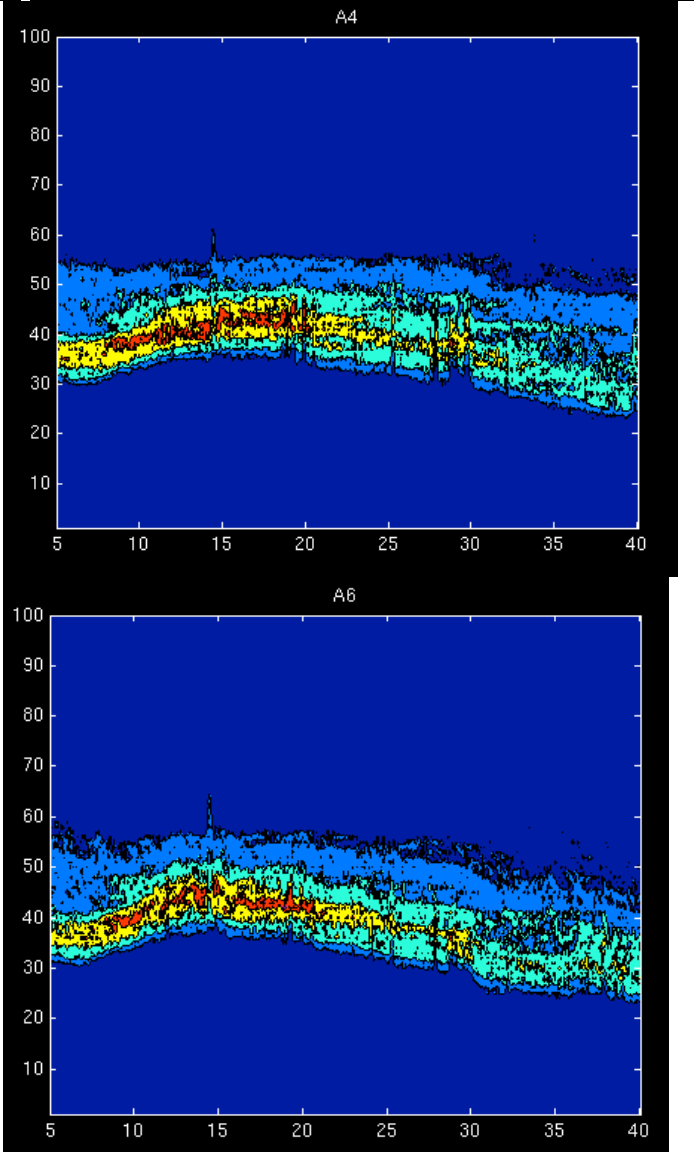

Spectra models for stations A1 through A6 (A1 is at the west end of the line). 

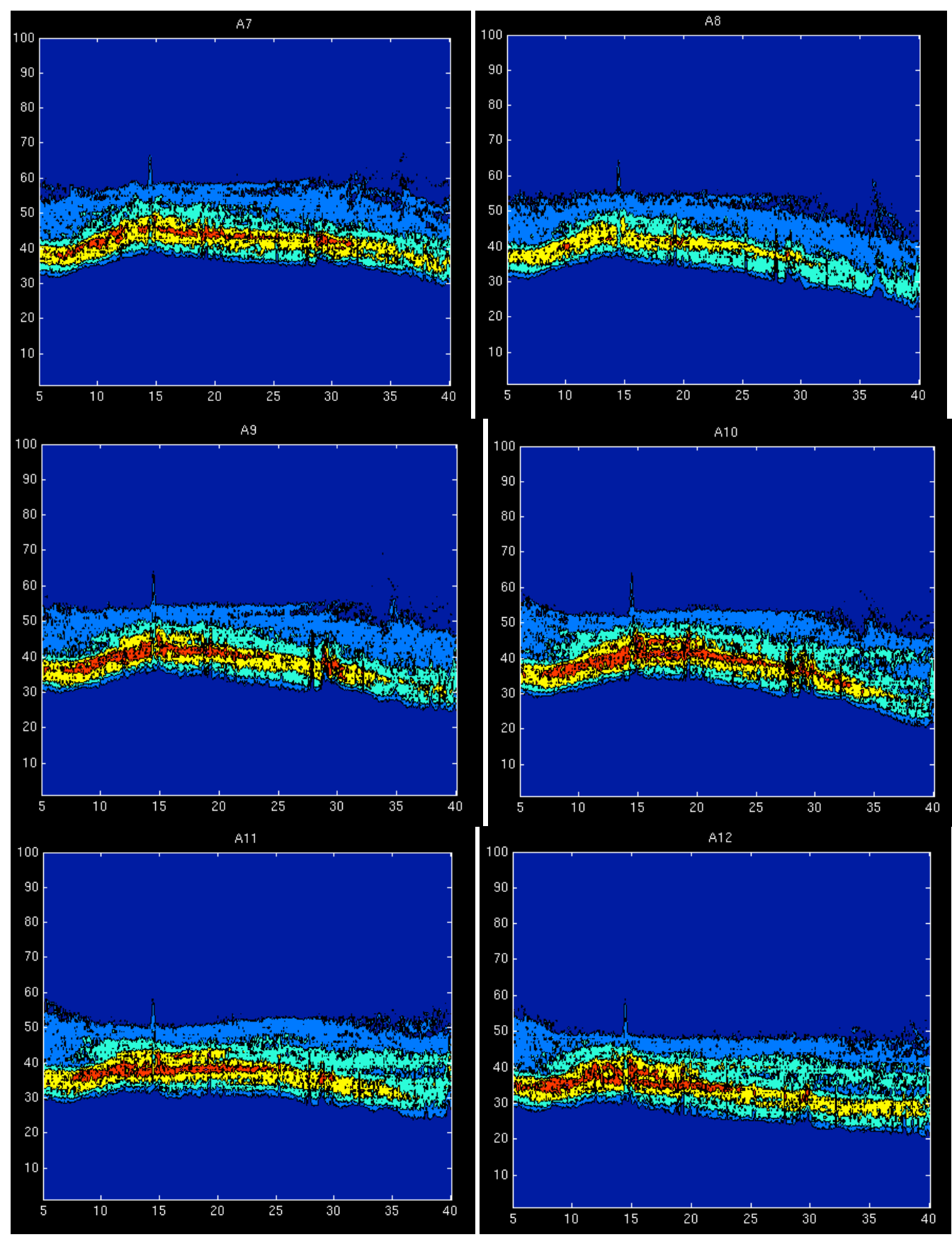

Spectra models for stations A7 through A12. These stations are closest to the underground damage zone, with station A8 closest to ground zero. 

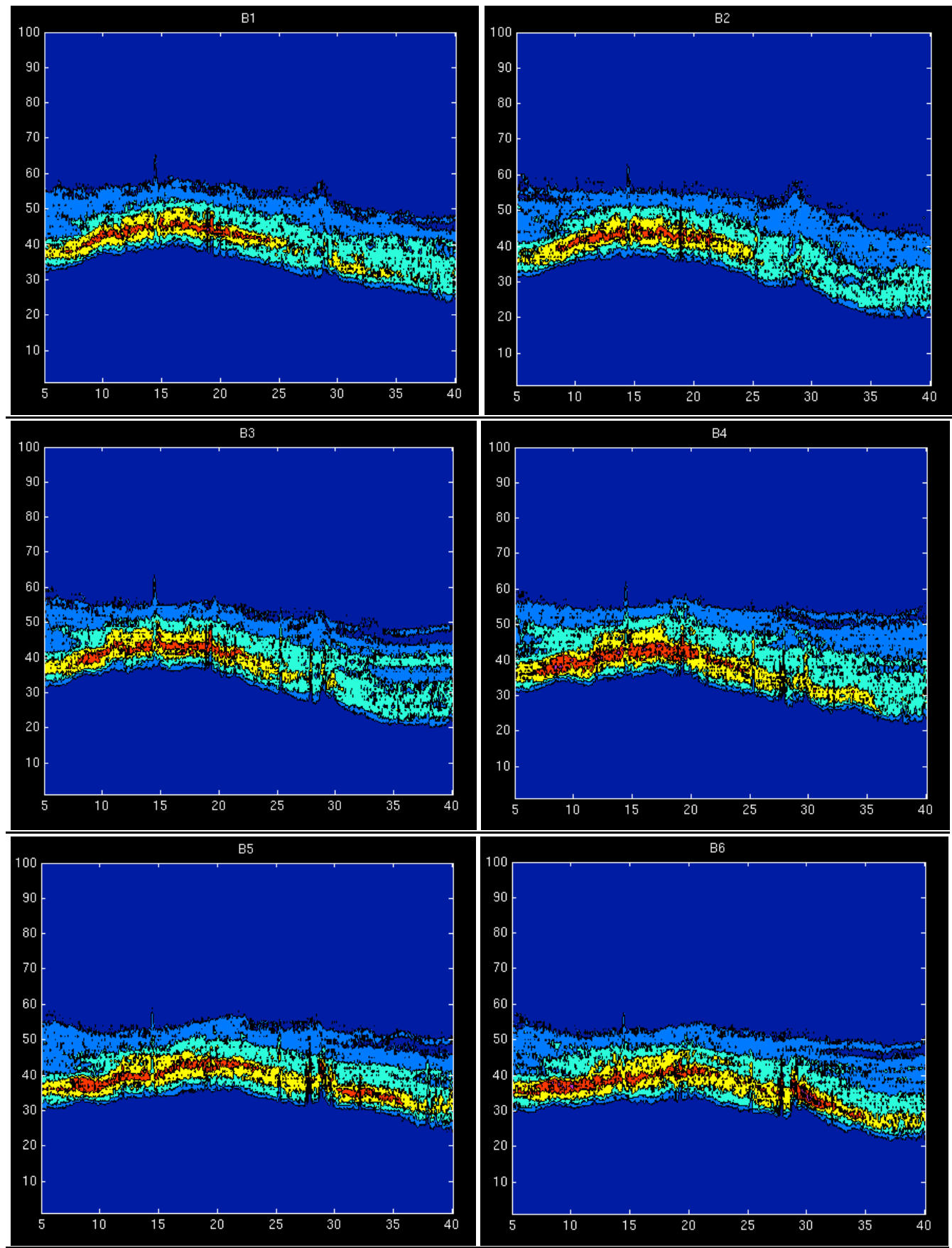

Spectral models for stations B1 through B6 on the western end of control line B. 
The next set of plots shown are noise model slices at $5 \mathrm{~Hz}$ frequency for all stations, with six plots (for each station) per figure. Each plot shows the number of spectra measured for a particular noise level (horizontal axis) at a the given frequency. In general, most of the noise occurs in the range of $30-45 \mathrm{db}$ for all of the stations. The "warmest" colors for the contour plots above correspond to noise levels of 50$70 \mathrm{db}$.

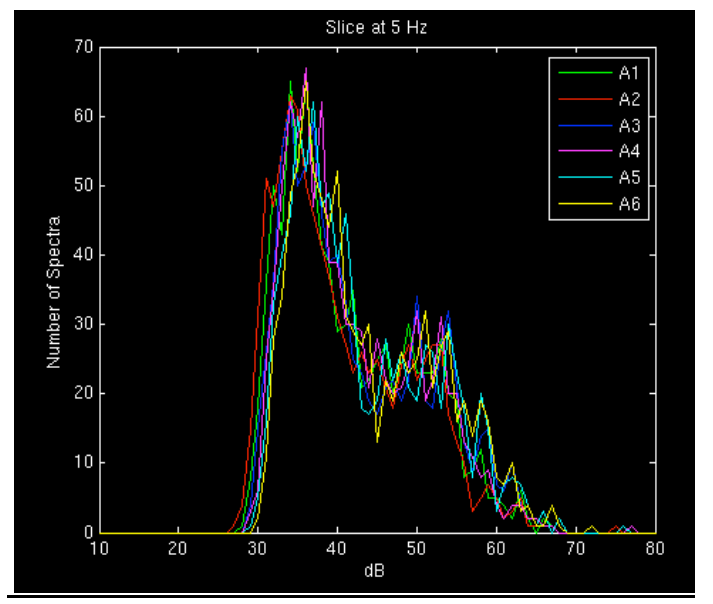

Slices of the noise model at $5 \mathrm{~Hz}$ for stations A1 through A6.

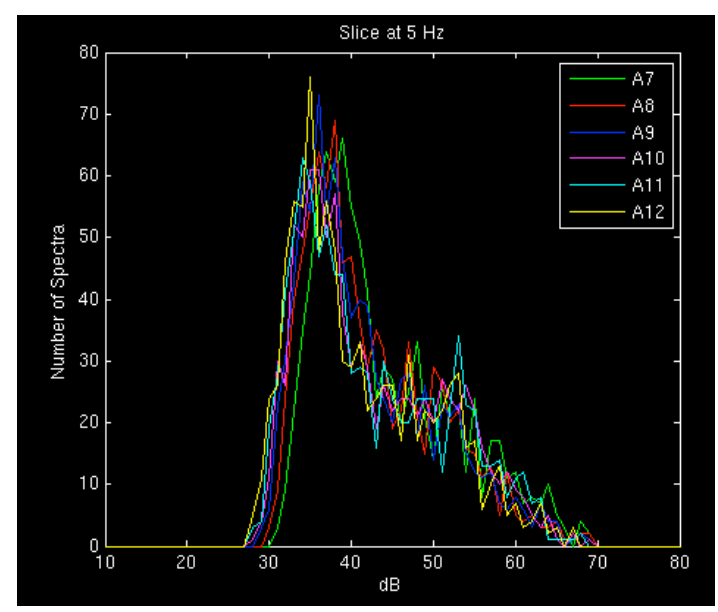

Slices of the noise model at $5 \mathrm{~Hz}$ for stations A7 though A12. 


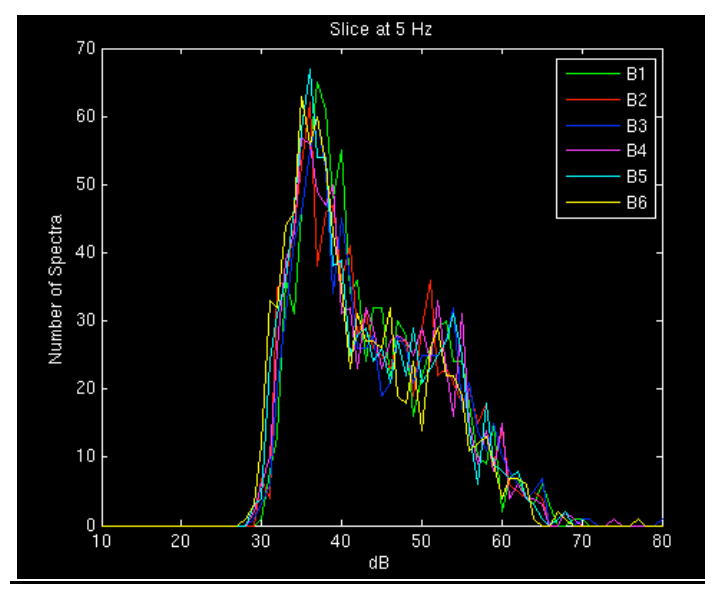

Slices of the noise model at $5 \mathrm{~Hz}$ for stations B1 through B6.

Since the noise models are computed at increments of $0.1 \mathrm{~Hz}$, plots like those above can be produced for any frequency desired between 0.1 and $40.0 \mathrm{~Hz}$. The ones shown for $5 \mathrm{~Hz}$ are typical. Plots at other frequencies are quite similar to those at 5 $\mathrm{Hz}$, especially at the lower frequencies. The plots at $5 \mathrm{~Hz}$ are almost bi-modal, with a "shoulder" at about $50 \mathrm{db}$ that is not seen for similar plots at 10 and $20 \mathrm{~Hz}$. There does not appear to be any type of signature in the spectra that would indicate differences between stations near the underground damage zone and those more distant. 


\section{Coherence Analysis}

Coherence was calculated using a program called cohere. The program prompts the user sequentially for the filename of the seismic waveform data and then asks for the data window length (usually 30 seconds), the number of windows (we used 40 for 1000 seconds of data, 150 for an hour of data, and 300 for two hours of data), and the correlation window length (we used 30 seconds for this also). The program produces the file coh.ab, which the user should rename for the particular station. Plots of the output are of coherence between 0 and 1 on the $y$-axis and frequency between 0 and $40 \mathrm{~Hz}$ on the $\mathrm{x}$-axis.

To run the coherence calculation, it is best to choose a long quiet period and cut the file to that length. The length of the reftek continuous files should each be 3600 seconds (one hour), but in practice file lengths were found to be variable and often less than one hour. Furthermore, on line A, the sensor polarity was found to be reversed for recorder 9E1D on channels 1,2, and 3. This had to be corrected before running the coherence calculations.

What follows is an extensive coherence comparison for one quiet period of 1000 seconds of data. The time period of the data is day 360 (Dec. 26), beginning hour 10:59 and the files are all cut between 500 and 1500 seconds.

Shown below is the line B (control line) nearest neighbor coherence comparison (coherence is calculated between a station and the one next to it along the line). Note that the station spacing (correlation length) is roughly the same for each comparison.

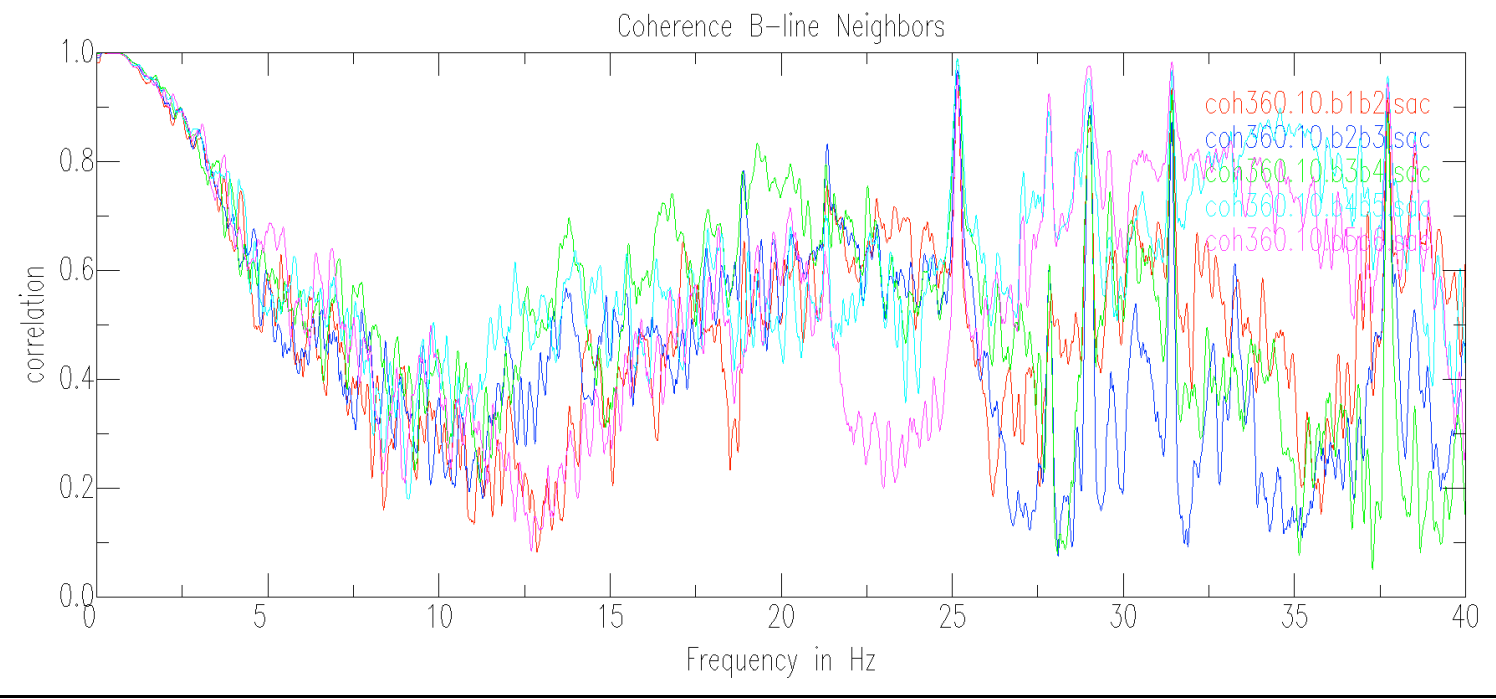

All traces show a similar coherence roll-off from $0-10 \mathrm{~Hz}$. Of note is that the B4-B5 coherence and B5-B6 coherence are markedly higher at frequencies between 25 and $40 \mathrm{~Hz}$. The overhead imagery indicates a change in terrain or vegetation between 
stations B4 and B5 (the surface west of B5 has presumably been scraped by construction equipment) that could be a possible cause the change in coherence.

The next plot shows the nearest neighbor comparison of the line A stations 1 - 6 .

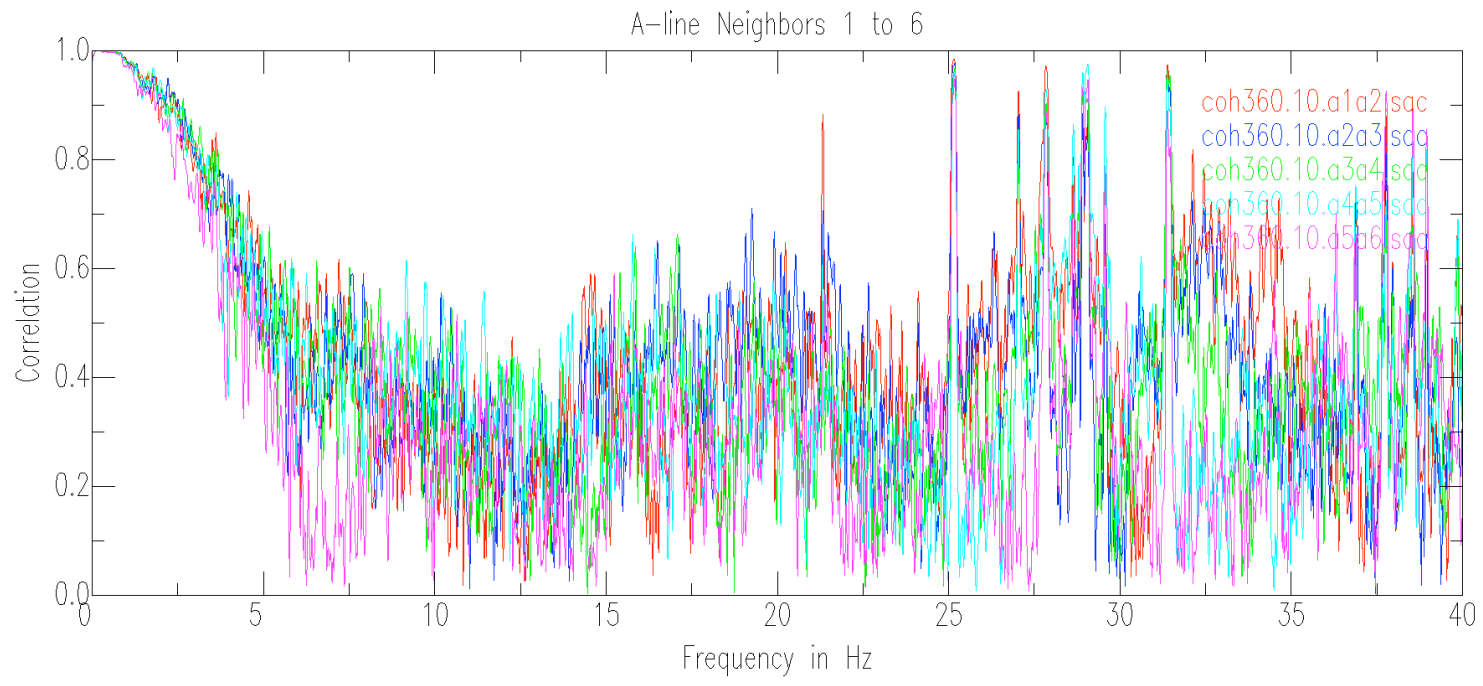

This suggests similar low frequency behavior for all traces up to about $6 \mathrm{~Hz}$, with more complex behavior at higher frequencies.

The next plot shows the nearest neighbor comparison of the line A stations 7 - 12 .

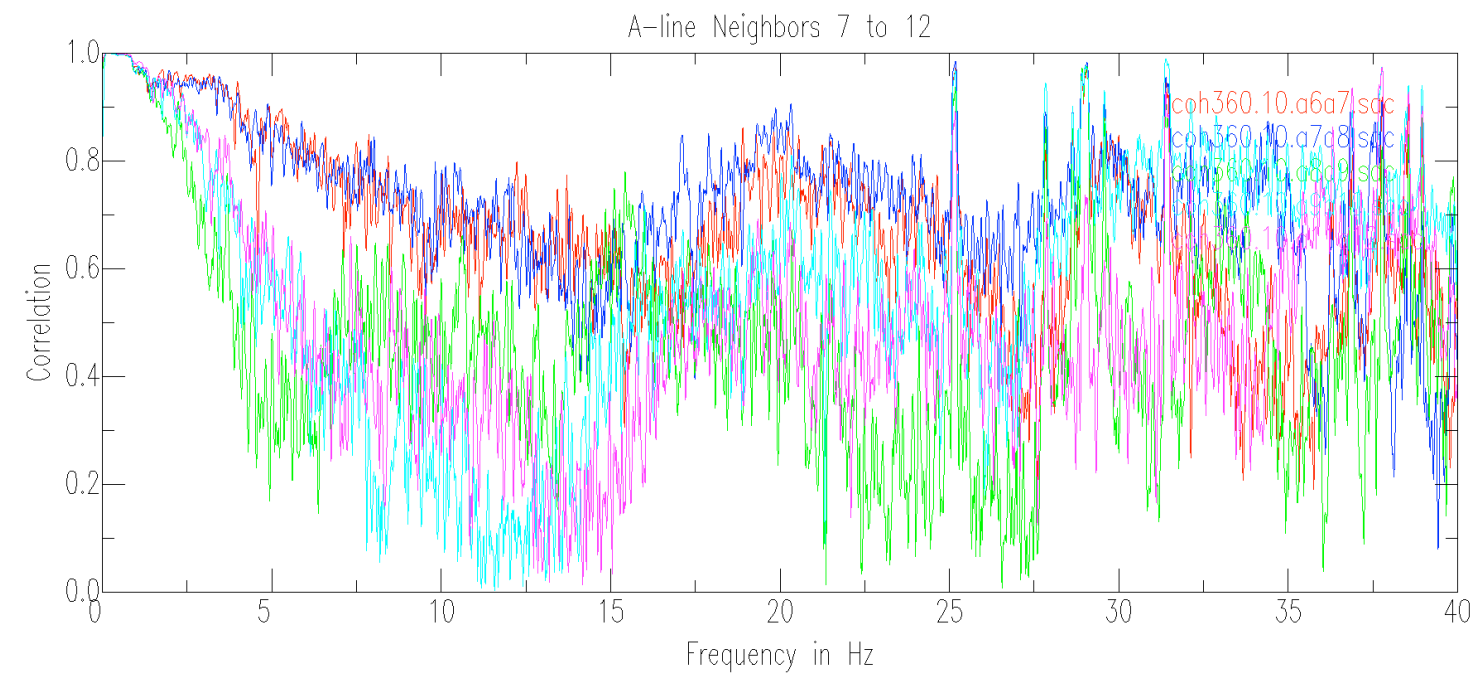

This plot shows a marked difference in coherence for A6-A7 and A7-A8 across the full bandwidth but particularly in the lower frequencies. However, it should be noted that the A6-A7 and A7-A8 station spacing is about half that of the other stations. This alone could account for the difference in coherence. This could be confirmed with line B since the B6-B7 and B7-B8 spacing is also about half; unfortunately, the second half of the B-line had no useable data.

The next plot verifies that the improvement in coherence in the previous plot was a station separation effect. 


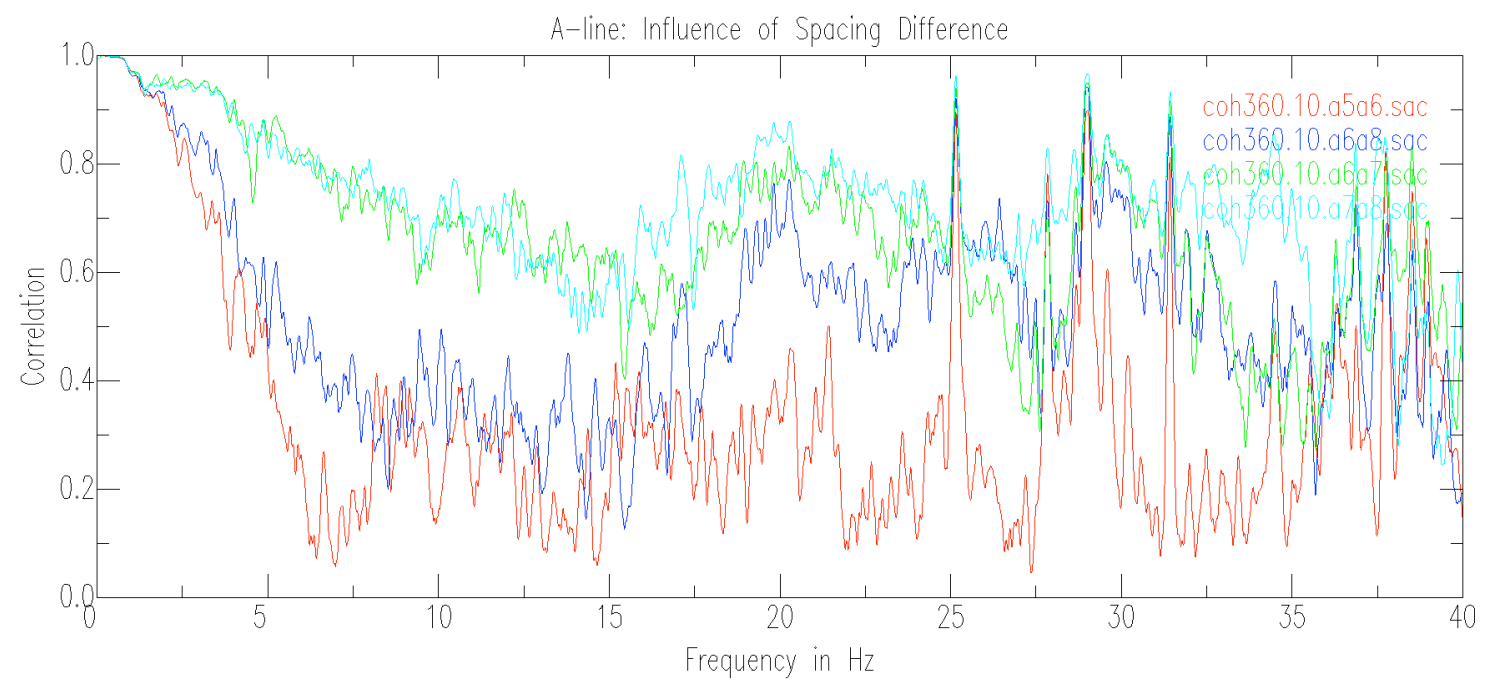

Here we compare the smaller spacing of A6-A7 (green) and A7-A8 (cyan) to A6-A8 (which is about the same spacing of other neighbors) and A5-A6. Clearly the coherence difference is dominantly a station separation effect and not a geological effect.

We next look at the coherence for a larger station separation by skipping neighbors. The following is for the $\mathrm{B}$ line:

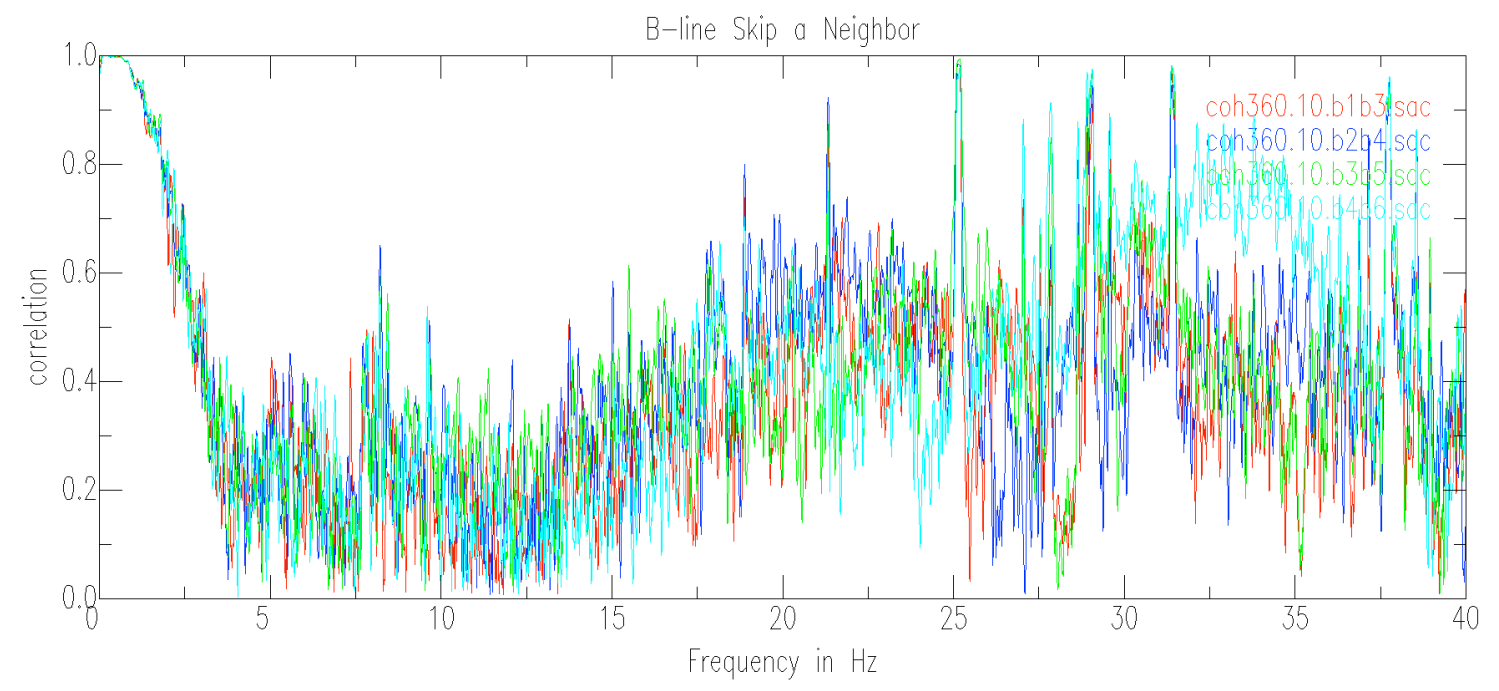

There is little difference between plots except the better coherence at high frequency for the B4-B6 (cyan) trace.

The following is the same type of plot for the line A. 


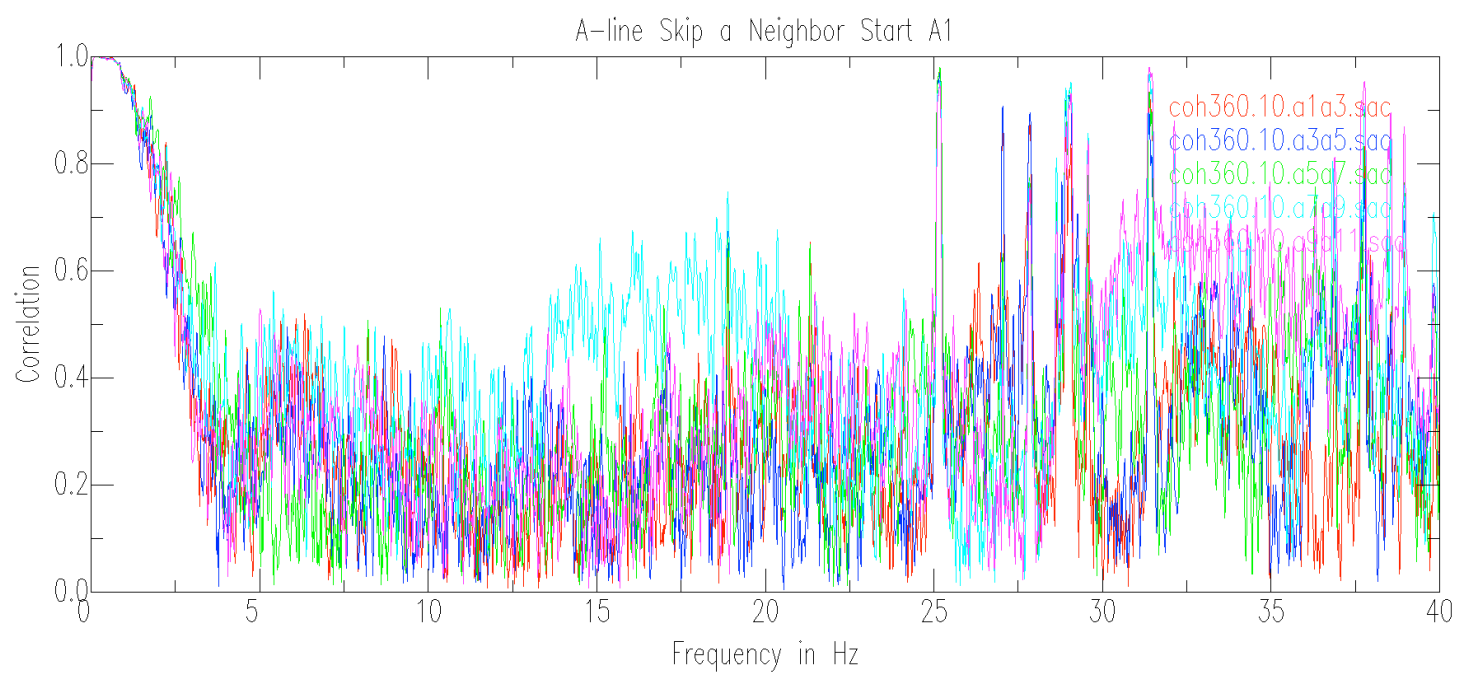

There appears to be no clear pattern here that would indicate effects from differences in the properties of the subsurface near line A.

These plots and analysis illustrate the difficulty of using correlation analysis for this type of study. Because the correlation between stations is strongly dependent on station spacing, the type of linear pattern of stations used here is probably not ideal for this type of study. Another problem is that subtle changes in near-surface materials (as noted for line B) can have unpredictable effects on signal correlations. 


\section{Analysis of Recorded Earthquakes}

In order to test a true "resonance seismic" approach, we selected some natural regional seismic events in the vicinity of the former Nevada Test Site (now called the National Nuclear Security Site (NNSS)) that would provide different paths between the event epicenter and the experiment seismic lines. The theory suggests that a seismic wave passing through the damage zone before arriving at the surface sensors would show differences from those not passing through the damage zone. Given the long path length between the earthquake source and the receiver compared to the relatively short path length that a wave would have within a damage zone from an underground explosion, it would seem that the net effect on the net travel time for the incoming wave passing through the damage zone would be very small. The only hope for this method might be to look for some kind of diffraction effects. A study of this is being done by a group in Kazakhstan, at the former test site used by the Soviet Union (Belyashov, 2010). That study relies on the use of a shear phase converted from a longitudinal phase of an incoming wave as it passes through the damage zone - which the author refers to as a PS converted phase. The first arrival of this phase and the ratio of the P and PS phase arrival times are used in an attempt to map the location of the damage zone in the subsurface. The method of Belyashov requires the use of three-component seismic data in order to identify the converted shear phase. Since we only have vertical component data for this study, we were not able to look for PS converted phases with our data.

The events analyzed are shown in the map below. The center star is the location of the sensors. The southernmost star is event EV1, the northernmost is event EV2, and the easternmost is event EV3. For these three events, EV2 has a path with the damage zone being between the source and receivers; the other two events serve as a control events for comparison. 


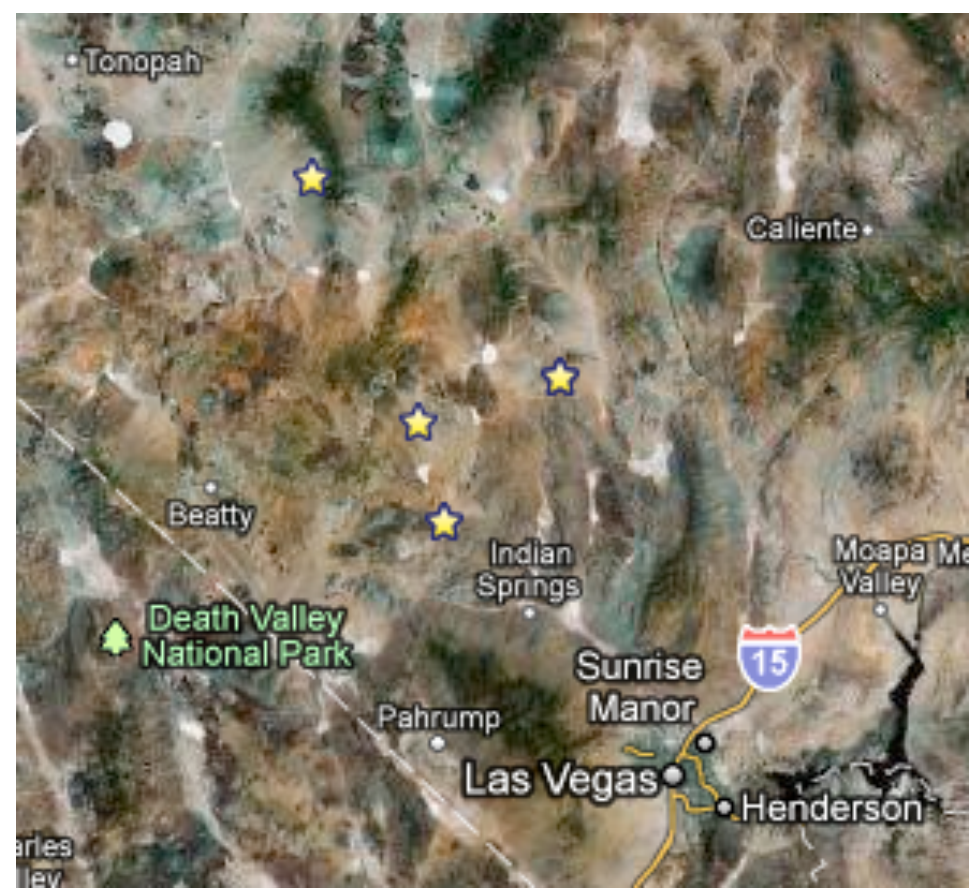

Map of the locations of the seismic lines used in this study and three local earthquakes used for seismic wave travel path analysis. The uppermost star is the location of event EV2, the lowest one is EV1, the most easterly is EV3, and the location of the receiver seismic lines is the more centrally located star.

Earthquake EV2 was a magnitude 1.7 event located at $37.75 \mathrm{~N},-116.41 \mathrm{~W}$, with a depth of $4 \mathrm{~km}$ (University of Nevada, Reno [UNR] catalog). This event occurred on day 340 at 21:12:27.462 and is about $79.3 \mathrm{~km}$ from the center part of line $\mathrm{A}$ at an azimuth of $336.6^{\circ}(\mathrm{NNW})$. It was recorded with good signal to noise ratio by all stations. The event waveforms at all stations are shown below. The total time of the records shown is 60 seconds, all A and B line traces have the same vertical scale.

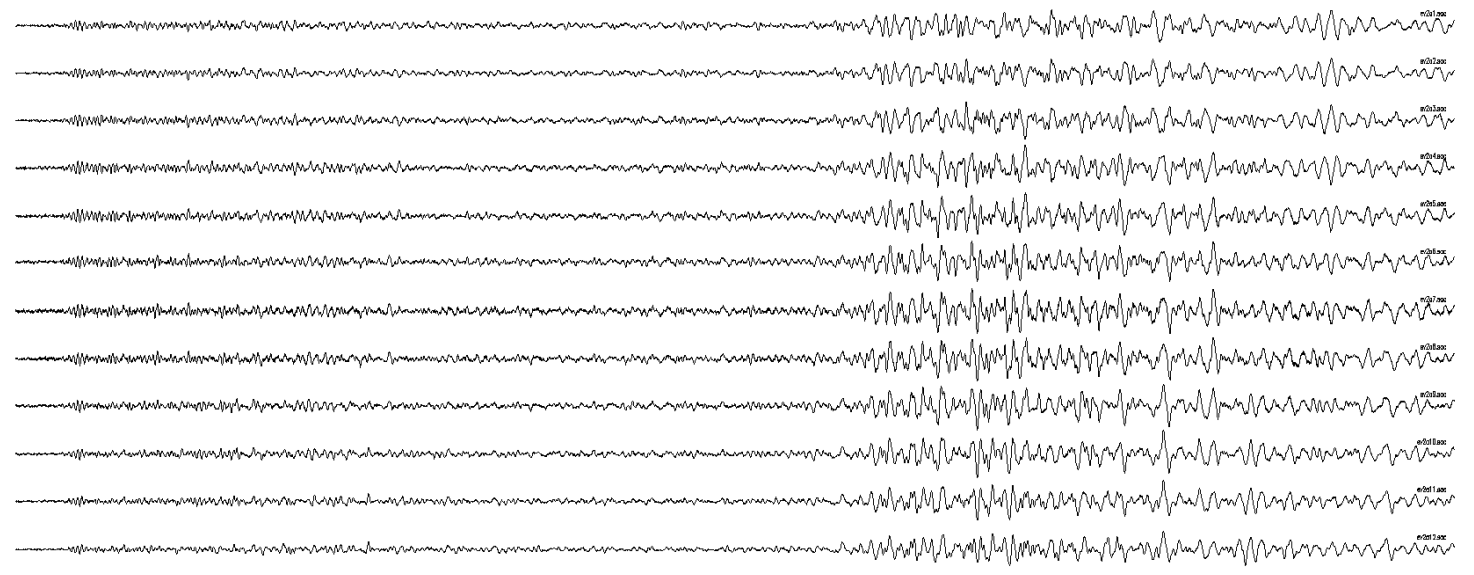

Waveforms recorded on line A (station A1 at top, A12 at bottom) of the arrival of signals from EV2 with paths passing through the UNE damage zone. Sixty seconds of the time record are shown; all traces have the same vertical scale. 


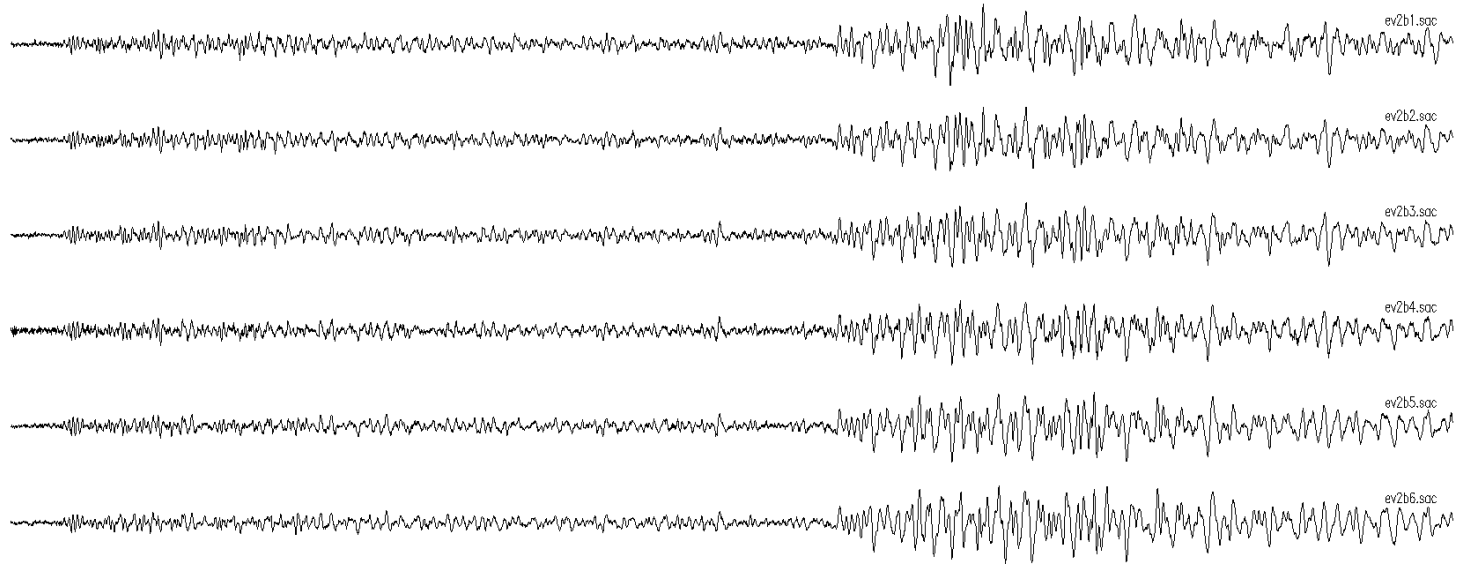

Waveforms recorded on the line B (station B1 at top, B6 at bottom) from earthquake EV2. Sixty second of time record are shown; all the traces have the same scale and are the same as for line A above.

The S phase arrival from EV2 appears just past the center part of the traces. The first arrival at the left hand side of the traces is probably not the P phase arrival from EV2 because the P-S time difference (about 32 seconds) is too long. The prominent arrival about 5 seconds before the $S$ phase arrival, seen best in the middle of the traces for line B, is probably the $\mathrm{P}$ arrival for EV2. There are some subtle differences between the shear wave coda (what appears after the first $\mathrm{S}$ arrival) at different stations, but there is nothing on these records that shows prominent effects on the arrivals that have passed through or near the damage zone. Effects from the damage zone from the underground explosion near profile line A should be most evident in the stations located in the central part of line (5-9).

It is instructive to look at the other two events, which occurred in locations where the travel path did pass through the explosion damage zone. Event EV1 was magnitude 1.6, occurring on 12/25/09 at 00:17:03.943 at $36.82 \mathrm{~N},-115.96 \mathrm{~W}$, depth given as zero (which means it was shallow, but couldn't be determined) by the UNR seismic catalog. This event is $33.5 \mathrm{~km}$ from the center of line $A$ at an azimuth of $156^{\circ}$ (SSE). The waveforms from the event recorded on lines A and B are shown below. The time record is 30 seconds long in this case and again all the traces have the same vertical scale. The initial P arrival occurs about 3.6 seconds before the $S$ phase. Similar station-to-station differences in the $S$ coda are seen for this event as were seen for EV2. This suggests that the differences are due to local site effects and not due to changes along the source to receiver path. 


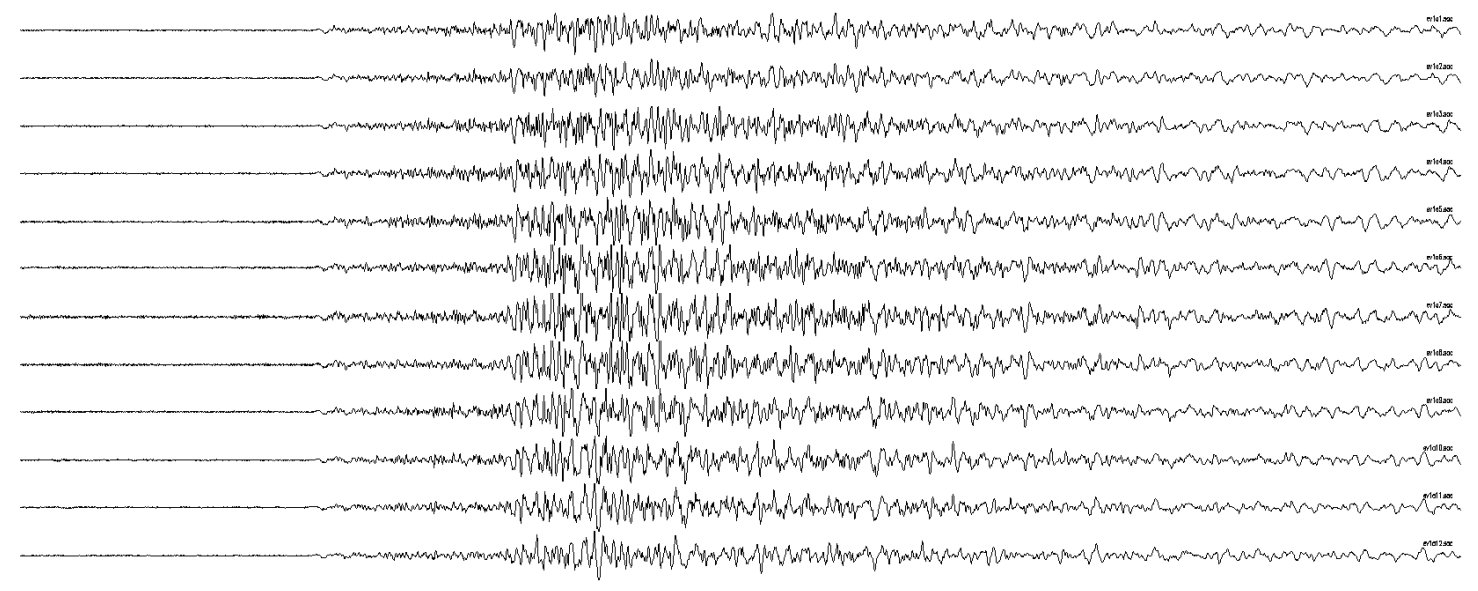

Thirty second time record of signals on line A from event EV1. All traces have the same vertical scale. Station A1 is the top trace, station A12 is the bottom trace.

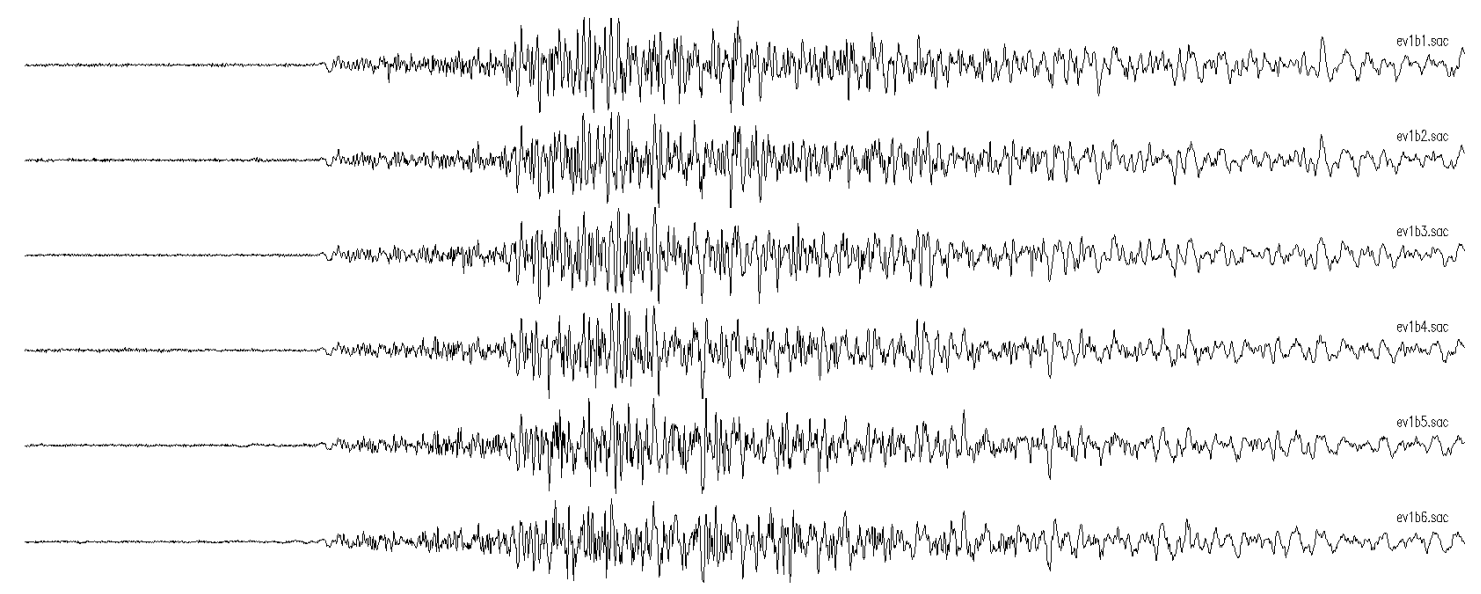

Thirty second time record of signals on line B from event EV1. All traces have the same vertical scale and are the same scale as for line A. Station B1 is the top trace, station B6 is the bottom trace.

EV3 was a M1.7 event located at $37.31 \mathrm{~N},-115.57 \mathrm{~W}$, with no depth estimated (UNR catalog). The event was on day 348 at 11:04:44.633 and was $49.9 \mathrm{~km}$ away from the center of line $A$ at an azimuth of $60.7^{\circ}$ (ENE) at a low angle to the length of the $A$ and $B$ lines. A forty-second record length of the event waveforms are shown below. There is about a 5.1 second delay between the first arrival of the P phase and arrival of the $\mathrm{S}$ phase. The waveforms here look very similar to those recorded for the other two events. 


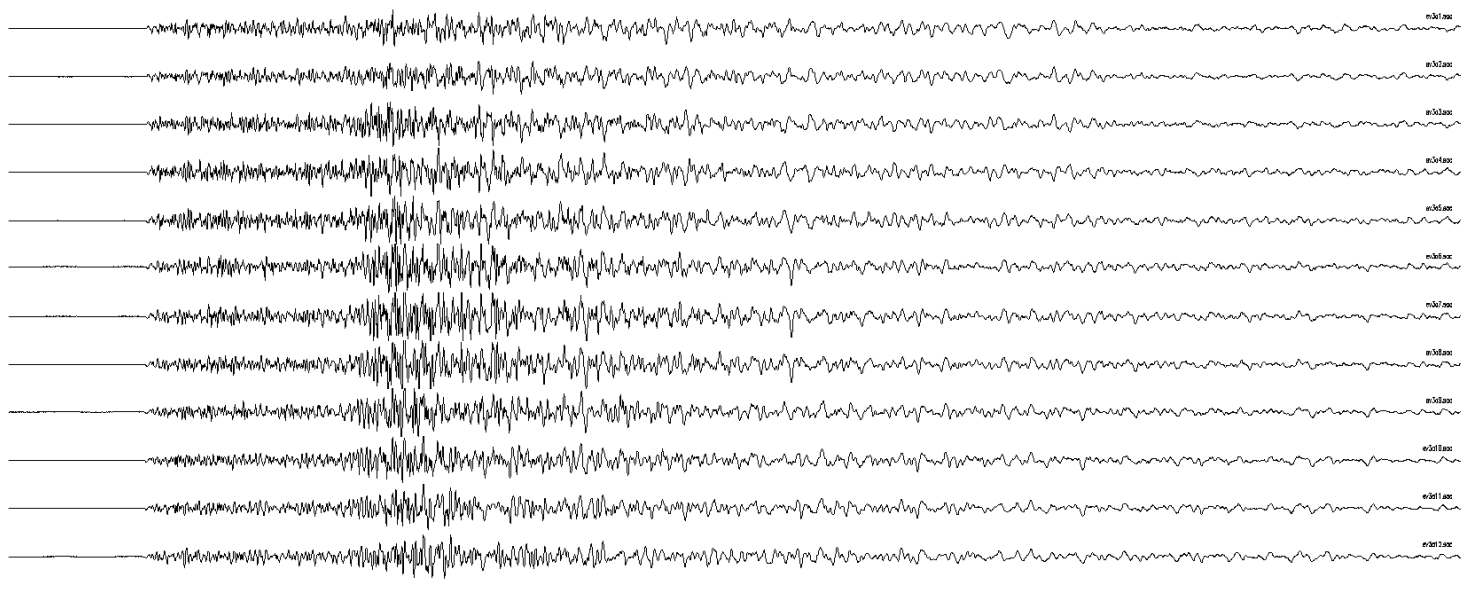

Forty second time record of signals on line A from event EV3. All traces have the same vertical scale. Station A1 is the top trace, station A12 is the bottom trace.

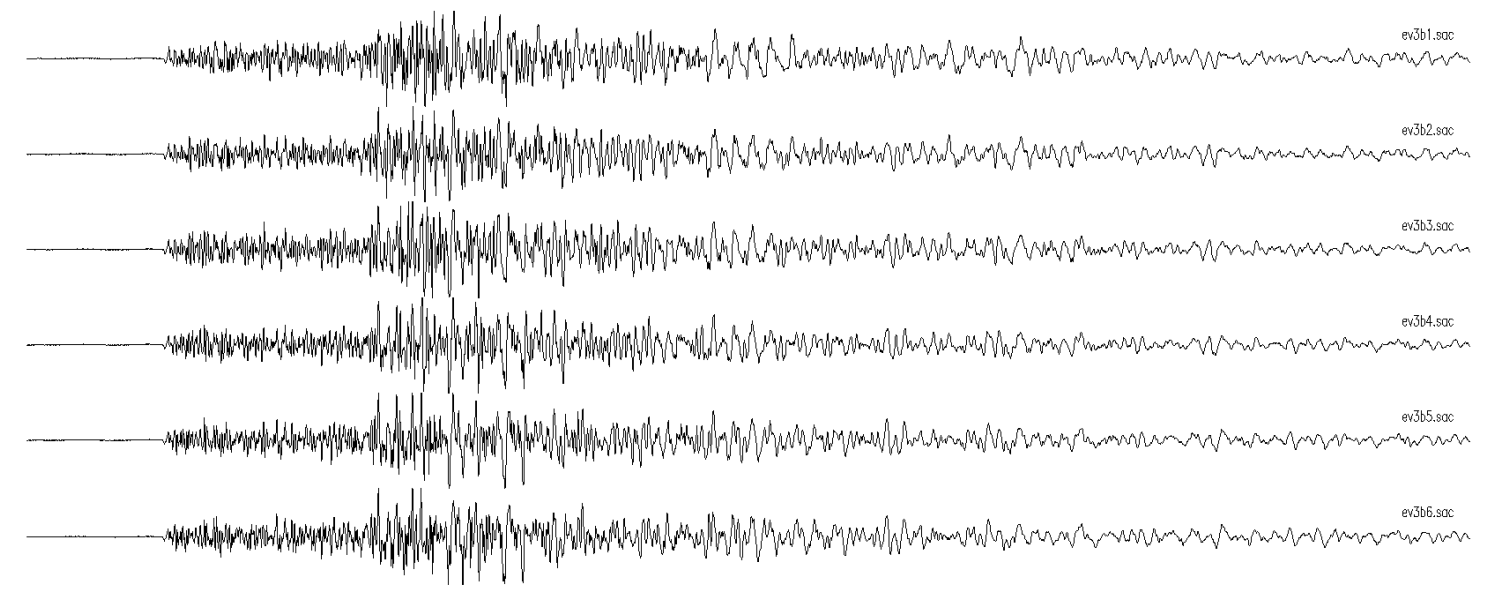

Forty second time record of signals on line B from event EV3. All traces have the same vertical scale and are the same scale as for line A. Station B1 is the top trace, station B6 is the bottom trace.

Instead of merely relying on visual observation of the traces, these data can also be analyzed in terms of total correlation. We can do this by applying a simple sliding window correlation to two waveforms. The sliding window correlation coefficient is defined mathematically as:

$$
\gamma_{w}(t)=\frac{\sum_{t-w / 2}^{t+w / 2} a_{b} b_{i}}{\sqrt{\sum_{t-w / 2}^{t+w / 2} a_{i}^{2} \sum_{t-w / 2}^{t+w / 2} b_{i}^{2}}}
$$

where $\mathrm{a}$ and $\mathrm{b}$ are two discreet signals, and $\mathrm{w}$ is the sliding window length. 
The idea behind using this type of correlation calculation is that, if there are some resonance effects occurring as the seismic waves pass through the damage zone from the UNE on the way to a receiver these might show up as a strong correlation when the signals are band passed prior to the calculation. However, first we have to look at what the correlation function above looks like when we compare stations pair-wise.

A Matlab script to carry out the correlation calculation was created, as shown below:

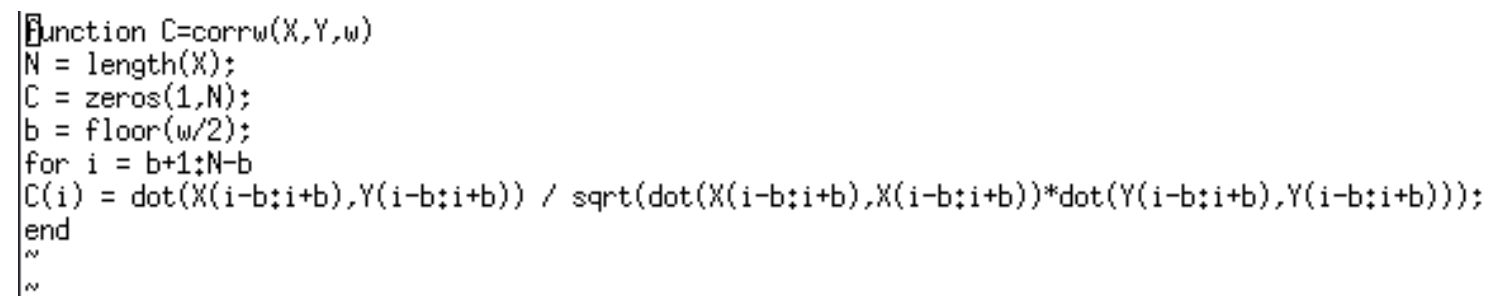

We applied the correlation window (corrw) function to event EV2, comparing the record from station $A 1$ to each other location on the line (e.g. A2, A3, A4,...). Respective traces from the A line (A1 - A6) were compared with counterparts on the B line (B1 - B6). Representative plots of the correlation function are shown below. The sliding window used is 1 second long (200 points) and advances one point at a time $(0.05 \mathrm{~s})$ over the 50 seconds of waveform data. Many of the plots show an abrupt change in the correlation function at the point where the signal from the event arrives. This indicates that the pre-event noise is not highly correlated and that the signals are highly correlated at the point where the signal arrives. The level of this signal correlation decreases as the distance between the stations being compared increases.

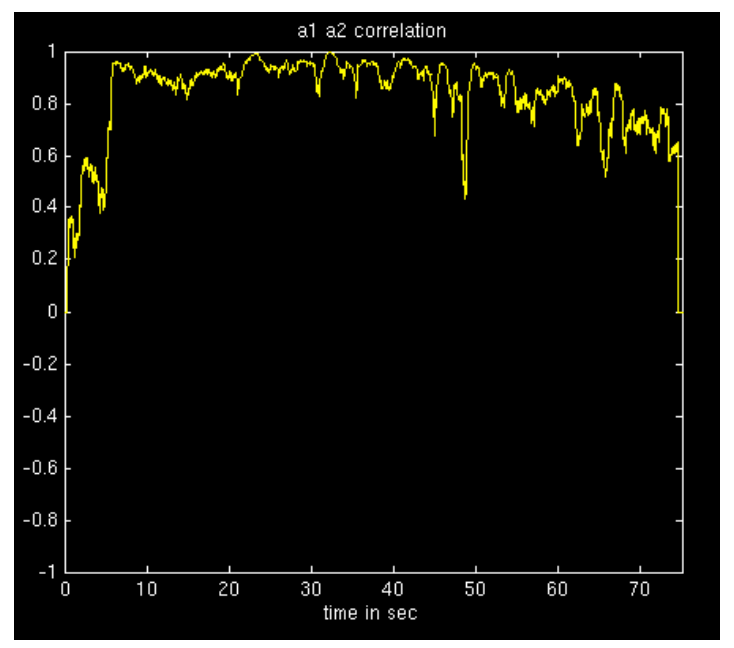

Moving window correlation function comparing signals from event EV2 at stations A1 and A2. Pre-event noise is poorly correlated; once the event signal arrives the correlation is much higher. 


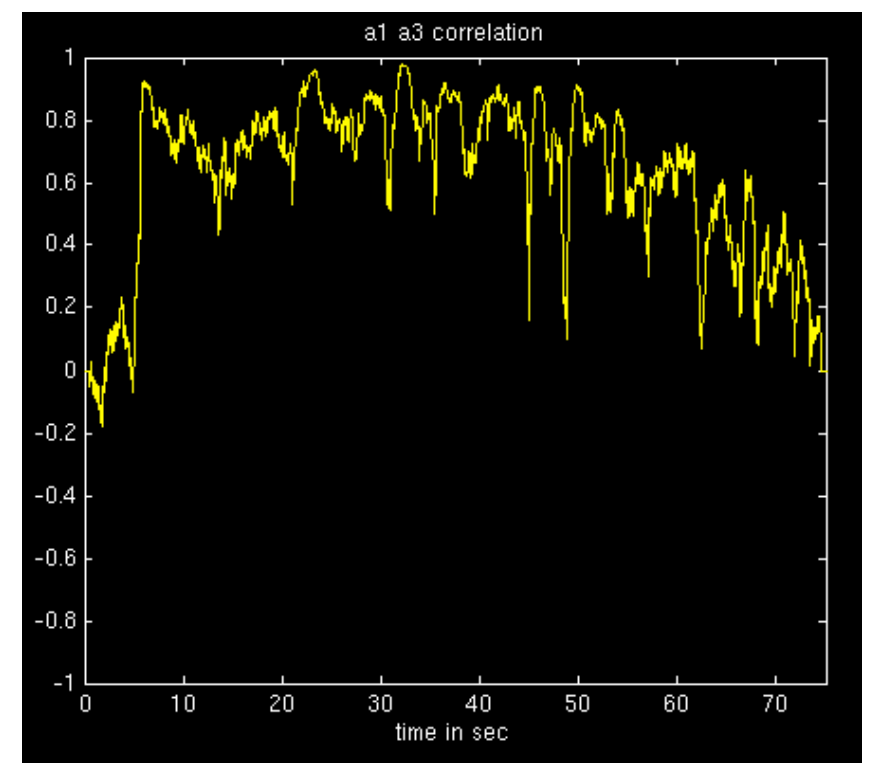

Moving window correlation function comparing signals from event EV2 at stations A1 and A3. Pre-event noise is poorly correlated; once the event signal arrives the correlation is much higher.

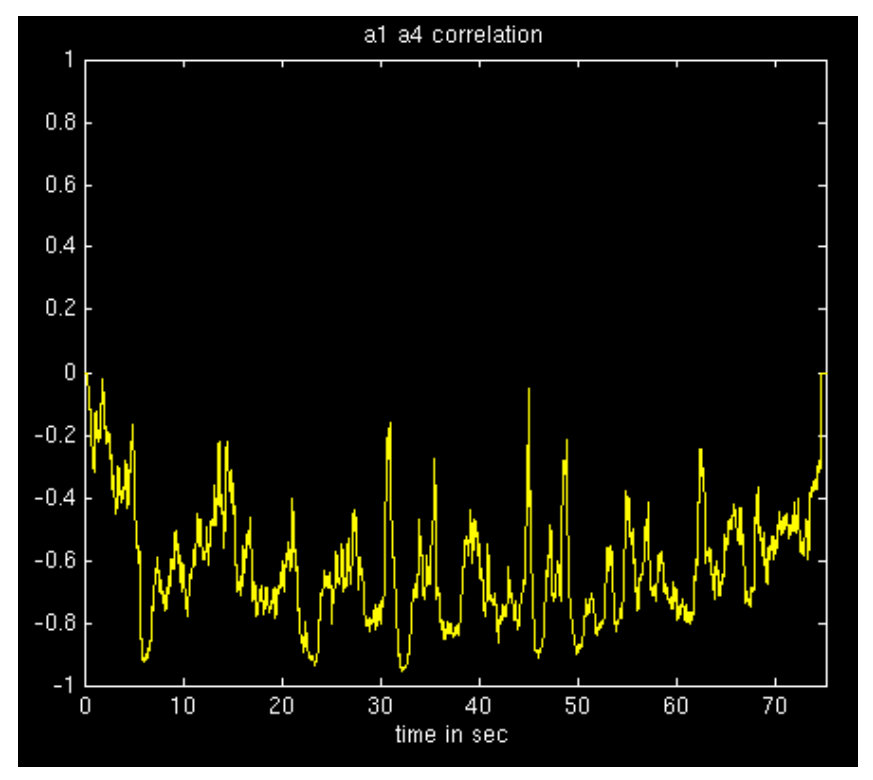

Moving window correlation function comparing signals from event EV2 at stations A1 and A4. Pre-event noise is poorly correlated; once the event signal arrives the correlation is much higher. (In this case, polarity of station A1 is reversed with respect to $\mathrm{A} 4$. 


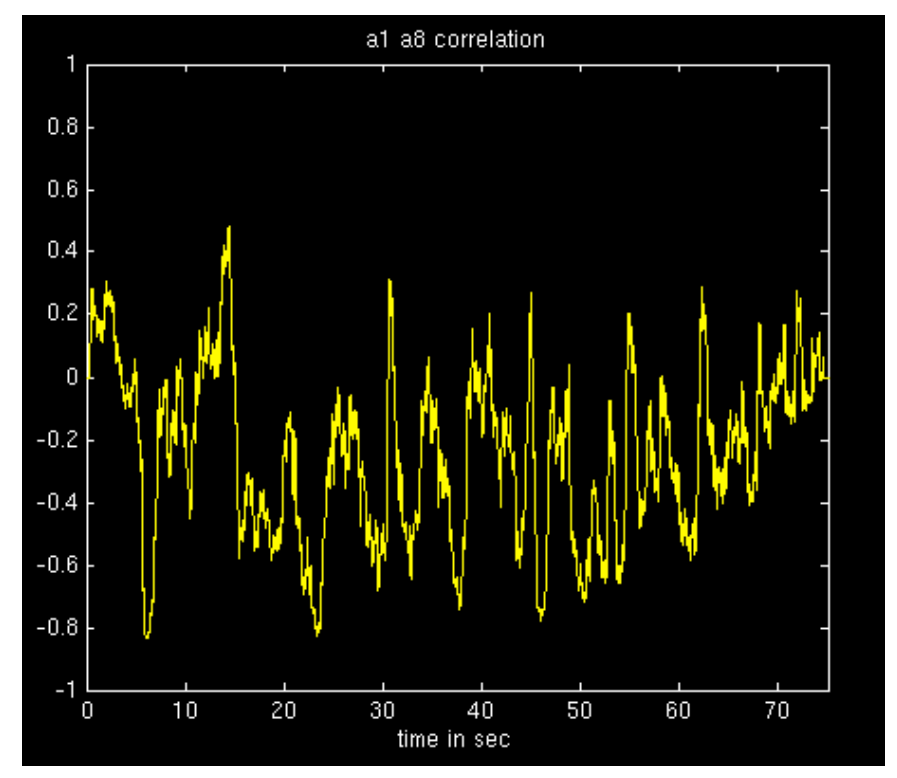

Moving window correlation function comparing signals from event EV2 at stations A1 and A8. Pre-event noise is poorly correlated; once the event signal arrives the correlation is much higher. (In this case, polarity of station A1 is reversed with respect to A4.

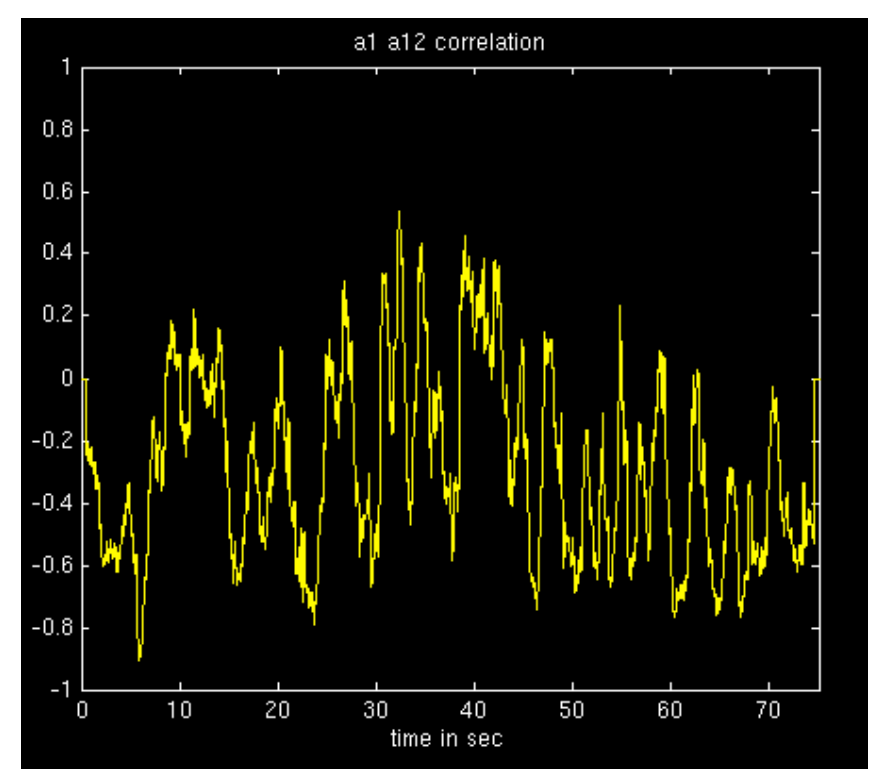

Moving window correlation function comparing signals from event EV2 at stations A1 and A12. Pre-event noise is poorly correlated; once the event signal arrives the correlation is much higher. (In this case, polarity of station A1 is reversed with respect to $\mathrm{A} 4$.

There are no obvious signatures in these correlation plots, other than the obvious (also true when the signals are compared visually) tendency for high correlation 
when the event signal arrives. Correlation of the signal later in the record seems to decrease with inter-station distance. Similar plots comparing stations on the B line with stations on the A line showed similar behavior, and there were no obvious signatures when the data were low-pass filtered at 10 and $20 \mathrm{~Hz}$. There are many more ways to compare data using these types of correlation plots, but there doesn't appear to be much more to be gained along these lines and with this data set.

\section{Conclusions}

There are no clear differences in the characteristics of signal and noise recorded by stations above the rubble/damage zone compared to stations that are not over the rubble/damage zone based on the analyses that we conducted. There is little doubt that a rubble/damage zone would alter seismic signals through scattering and attenuation properties that are different from the undisturbed host rock. One difficulty is the relatively small proportion of the travel path between an event and a receiver seismometer that is traversed within the damaged zone. In addition, such effects are only one of many that will affect seismic signals and noise variation between sensors. Site effects can be a major source of variation, through soil differences and coupling/sensor emplacement differences. Instrument variation can be a contributor to recorded waveform variation through alignment/leveling errors and calibration differences. Finally, the natural heterogeneity of the geology in the deployment region could be the dominant source of waveform variation. These natural sources of variation probably dominate the observed variation and obscure any variations controlled by the rubble/damage zone.

These results do not mean all hope is lost. In an on-site inspection scenario, the inspection team will probably be arriving on the scene of a suspect event within days to weeks after a detonation. In this case, even though aftershock rates and magnitudes have decreased below a level that allows individual aftershock events to be detected, there still may be elevated background noise related to aftershock stress adjustments. These are likely to occur in the frequency range of 2-15 Hz. This concept could be tested by recording continuous seismic data from a surface array of seismometers after an underground chemical explosion. Another approach, for testing of the resonance concept, would be to carry out a modeling study to determine the frequency band where the rubble zone has the greatest impact on seismic signal variation so that the instrumentation and analysis can focus on that region of the spectrum. As will be noted below, new types of instrumentation can be deployed and new analysis methods tried that have not been applied to this problem before. The concepts pursued by Belyashov, in which a P-S converted phase from distant events is used should be further explored, either by trying to duplicate his results using arrays of three-component instruments, or by acquiring more information about the approach he is applying.

The use of noise cross-correlation methods to characterize low frequency surface waves in the crust as become a common practice in seismology in recent years. The method relies on calculation of the noise correlation between two stations for long 
time intervals (months) of data. The correlated signal that comes out of this method is the low frequency surface wave, so the method can be used to map out surface wave velocity variations in the crust in areas with a high density of seismic stations. A method similar to this could be tried in looking for effects of sub-surface damage zones by having stations surrounding the zone of interest. This would allow the analysis to concentrate on effects between the stations and thus the path-length effects would be much reduced. Changes in the surface wave velocity as affected by the underground damage zone might possibly be measureable in this type of configuration.

Finally, several computational techniques and algorithms were developed in the course of this study that will be of particular use in future experiments. Several scripts were developed to allow the raw field data (Reftek format) to be converted to UNIX formats for later data processing. Other scripts were developed to create the average noise files and combine them into formats for producing the plots shown in this document. Other scripts (both SAC and MATLAB) were developed to carry out correlation calculations. Many of these processes and scripts are described in the Appendix of this report.

\section{Notes On a Future Experiment}

As noted above, a collection campaign of continuous seismic data for a period of several weeks following an underground chemical explosion would allow assessment of the possibility of using passive noise measurements as a way of locating the hypocenter of an explosion a short time after it has taken place. Our analysis here suggests that this approach does not work well for events detonated tens of years ago.

For the experiment deployed for this study, the cost to field the instruments was low and the responsiveness of the NSTech personnel and the regularity of the field data collection and disbursement of data to LLNL was good. However, there were a number of problems with the data collected:

1) One of the 4 recorders (half of B-line) was not recording seismic data for the duration of the experiment. This problem was only discovered late in the data collection campaign.

2) The data files, which were supposed to each be 1-hour in length, were all an hour or less in length with data gaps in the continuous record.

3) The polarity of some sensors was reversed. This should have been checked when the instruments were first deployed.

4) For best correlation comparisons, the station should be the same, within a few meters.

The next experiment should try to provide a data quality check system, ideally by the group responsible for the deployment and data collection, since the scientists that will eventually analyze the data my not be able to analyze data early in the 
experiment. Once fielded and stable, a representative data segment needs to be evaluated for seismic data quality, file length and polarity.

There do not appear to be consistent differences in spectra for stations over a shot zone and a reference away from it. The coherence does not appear to be a useful diagnostic either, although we have not exhausted all possible comparisons. This experiment could not test Belyashov's P-S conversion approach because the deployment used vertical components only. The geometry of a line over the shot zone and a reference line away from it seems a good one that should be emulated in a future experiment. It will be important for any future coherence analysis (say using the horizontal components) that the sensors are a fixed spacing apart since we know that coherence is strongly dependent on the spacing.

We recommend that a future experiment use 3-component seismometers so that other methods, like the Kazakh one, can be tested. Also, spectral noise models and coherence may yield different results when applied to horizontal components of the wave field.

We also recommend that a new type of instrument be deployed and co-located with the three-component seismometers. This instrument is a triaxial rotational seismometer. The following discussion (with references) gives some of the possible ways the rotational and translational records can be used to gain new insight into the wavefield and perhaps identify a shot zone region (through S phase velocity, P-S scattering, etc.).

Since the rotational component of motion about the vertical is sensitive to horizontally polarized shear waves $(\mathrm{SH})$ but not to $\mathrm{P}$ converted to vertically polarized shear waves $(\mathrm{P}-$ $\mathrm{SV}$ ) waves, the SH arrival at the station can be more precisely determined (Takeo, 1997). This can help define a better processing window for $\mathrm{SH}$ energy subsequent to arrival. A back-azimuth to the $\mathrm{SH}$ wave source can then be calculated using both the translational and rotational components. It has been shown that rotational motion around the vertical axis is observed in the P-coda of some earthquakes using a ring laser system (Pham, 2009). Since there should be no rotational motion around the vertical in spherically symmetric isotropic medium from $\mathrm{P}$ and P-SV scattering, this was shown to be the result of P-SH scattering in the crust. Back azimuths were obtained by rotating the transverse components to achieve a maximum in the P-coda-windowed cross correlation of the transverse acceleration and rotational angular velocity about the vertical. Applying this method to events recorded by an OSI deployment will allow us to quantify the partitioning of SH energy into a crustal scattered component from $\mathrm{P}$ waves and a direct component originating at or near the source and thereby get at the scattered S-wave energy and how it varies from station to station due to local scattering. If we compare the translational acceleration with the vertical rotation, under plane wave assumptions, the signals should be highly correlated (Schreibner, 2009) and the proportionality constant is double the SH phase velocity at the station. Calculating the variation in the station phase velocity for a given event recorded by numerous stations in a deployment may also give 
some indication of a local anomalous region such as that associated with an underground test rubble zone.

This work performed under the auspices of the U.S. Department of Energy by Lawrence Livermore National Laboratory under Contract DE-AC52-07NA27344.

\section{$\underline{\text { References }}$}

2000, United States Nuclear Tests, July 1945 through September 1992, DOENV-209REV 15.

Belyashov, A., V. Shaytorov, A. Drozdov, K. Kadyrzhanov, Underground Nuclear Explosion Related Signatures in the Geophysical Fields at the Semipalatinsk Test Site, Presented at On-Site Inspection Workshop 17, Baden, Austria, May 2010.

Pham, N.D., H. Igel, J. Wassermann, M. Kaser, J. de la Puente, U. Schreiber, Observations and Modeling of Rotational Signals in the P Coda: Constraints on Crustal Scattering, Bull. Seism. Soc. Am., 99, 1315-1332, 2009.

Schreiber, A. Valikoseltsev, First Comparison of Array-Derived Rotational Ground Motions with Direct Ring Laser Measurements, Bull. Seism. Soc. Am., 96, 2059-2071, 2006.

Takeo, M., What Can be Learned From Rotational Motions Excited by Earthquakes, Geophys. J. Int., 129, 319-329, 1997.

Watkins, J., R. Godson, and K. Watson, 1967, Seismic Detection of Near-Surface Cavities, U.S. Geologic Survey Professional Paper 599-A 
Appendix

\section{Calculation of Background Noise Spectra:}

The background noise spectra were calculated for every waveform file in the dataset. Some waveform files caused the sac macro to fail, mostly due to a slight file length problem. No attempt was made to recover these lost spectra since this was a less than $10 \%$ random event and the time spent was not deemed justified. Consequently the total spectra count for each station spectra directory will differ.

The spectra are calculated using the seismic analysis code, SAC. A SAC macro calculates the spectra and a controlling script loops over all the waveform files in a user supplied list.

A macro script for processing data from line A is shown below. Line A utilizes two recorders so there is initial logic in the script to associate channels with station identifiers:

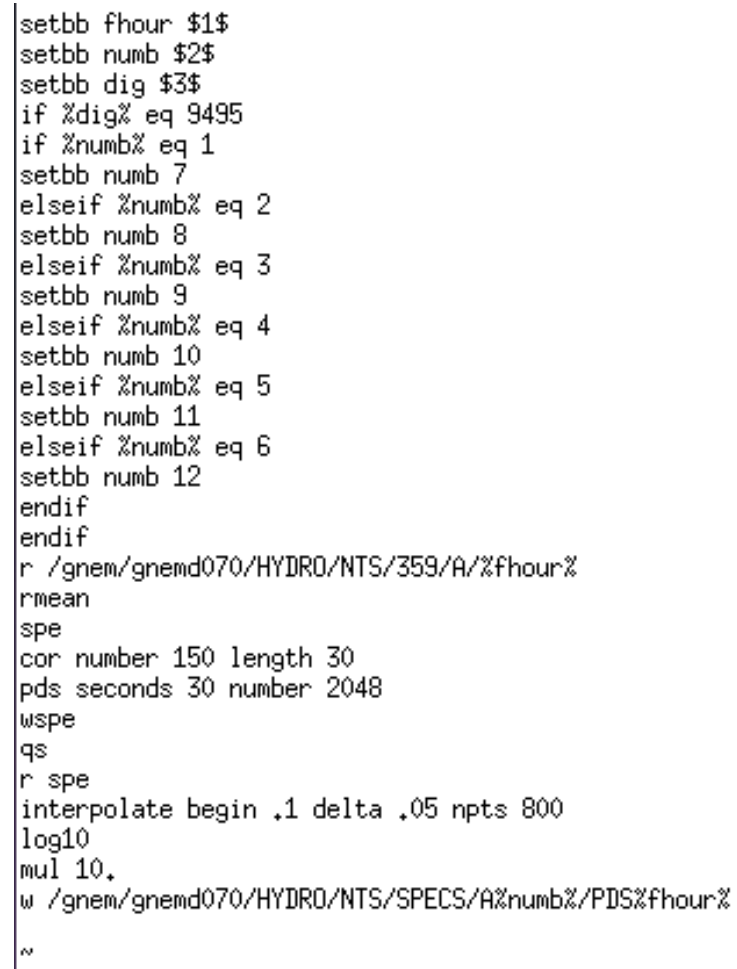

The macro for the line B is shown below. Only one recorder was usable so no station identified logic is necessary: 


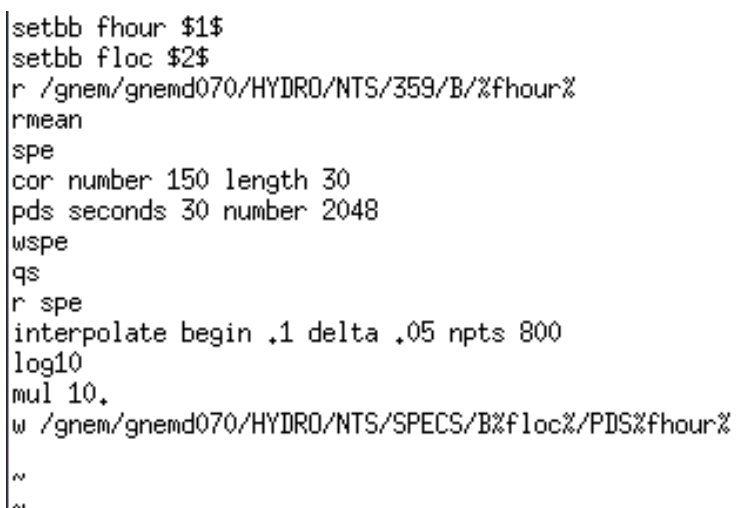

The controlling script is shown next. This controls the repeated execution of sac for each waveform in the file list.

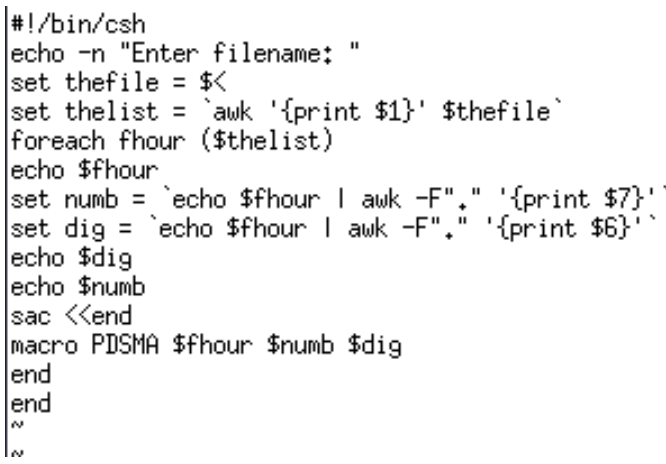

The spectra are power density calculations. In the waveform file, the data mean is removed. The correlation function is calculated using 15030 -second windows; this is a $25 \%$ sliding overlap given that the file length is 3600 seconds. The power density spectra are calculated from the correlation function using a $30 \mathrm{~s}$ window length. 


\section{Calculation of Noise Models From Spectra:}

Noise models were constructed for each station sensor by utilizing all the spectra calculated in the analysis period. The number of spectra used for each station varies slightly from station to station but is nominally 915 , which means the noise models are based on about 900 hours of recorded data.

A simple matlab script, NTSnm.m, creates a noise model from the spectra directory. The script is shown below:

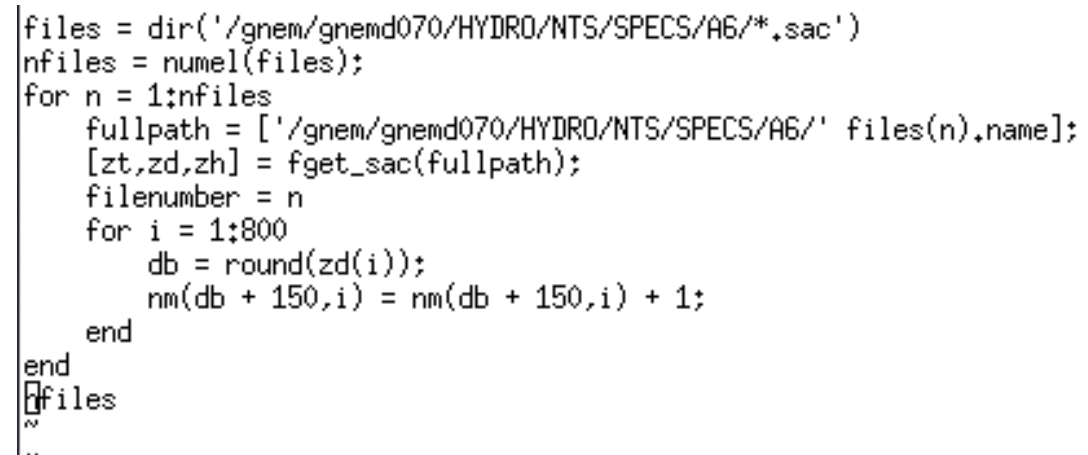

The procedure for creating a noise model is to first edit the script so that the correct station data is accessed (e.g. A6, B3,..). Then run MATLAB in the NTS directory. In the command window type:

$\mathrm{nm}=\operatorname{zeros}(200,800)$

NTSnm

The final count of spectra will be shown. The matrix nm is the noise model. Save the workspace as a .mat file to save the noise model. 


\section{Making Various Plots from the Noise Models in MATLAB:}

To manipulate and plot the noise model in MATLAB, the model of interest must be imported into MATLAB. The matrix $\mathrm{nm}$ is the model and only this variable is needed.

For contour plots-

$\mathrm{x}=5: .05: 40.05$

$\mathrm{y}=1: 100$

$\mathrm{nmx}=\mathrm{nm}(1: 100,99: 800)$

contourf(x,y,nmx,5)

For maximum probability plots-

$\mathrm{x}=.1: .05: 40.05$

$[\mathrm{mx}, \mathrm{r}]=\max (\mathrm{nm})$

$\operatorname{plot}(\mathrm{x}, \mathrm{r})$

To smooth (use moveavg.m)-

Ys = moveavg $(\mathrm{r}, 10)(10 \mathrm{pts}$ on each side $)$

$\operatorname{plot}(\mathrm{x}, \mathrm{Ys})$

For confidence interval plots (use conf.m)-

$\mathrm{Y} 10=\operatorname{conf}(\mathrm{nm}, 10,19308)(10 \%$ confidence $19308 \mathrm{DG}$ spectra $)$

$\operatorname{plot}(\mathrm{x}, \mathrm{Y} 10)$

To slice plots at a fixed frequency-

$\mathrm{x}=10: 80$

$\operatorname{plot}\left(\mathrm{x}, \mathrm{nm}(10: 80,799), \mathrm{rr}^{\prime}\right)$

for multiple, put hold on and keep loading new noise models and incrementing color (i.e. 'r', 'b', 'm' ,..). To make legend:

legend('A1', 'A2','A3') 


\section{Directory Structure:}

The NTS OSI Seismic Experiment data resides in the following directory on sigma957: /gnem/gnemd070/HYDRO/NTS. The data is organized by day, then by seismic line (A or B):

NTS

$356 \quad 357 \quad 358 \quad 359 .$.

A B A B A B A B

Within the A and B directories are all the waveform data for that day in 1-hour-long files.

Two other directories under NTS are worth noting: SCRIPTS and SPECS. SCRIPTS contains all the processing scripts used for various data analyses. SPECS contains all the spectra calculated from the waveform data. Under SPECS are the station identifiers: A1, A2, A3, .. and these directories contain all the spectra calculated for that station. 


\section{Data Conversion Scripts:}

The data conversion is a two-step process. First, the data is converted from reftek format to segy format, then the data is converted from segy format to sac format. The scripts below require an input file that is a list of every file you want to convert. The list file is easily generated by typing: ls > filename (remember to edit the file and remove filename from the list). The program the script runs is ref2segy. The script is necessary if the header is not being read properly and the program is prompting the user for input. To run the script, type csh ref2segy.csh and then give the filename prompted for. The script is listed below. Edit the script for different sample rates, etc..

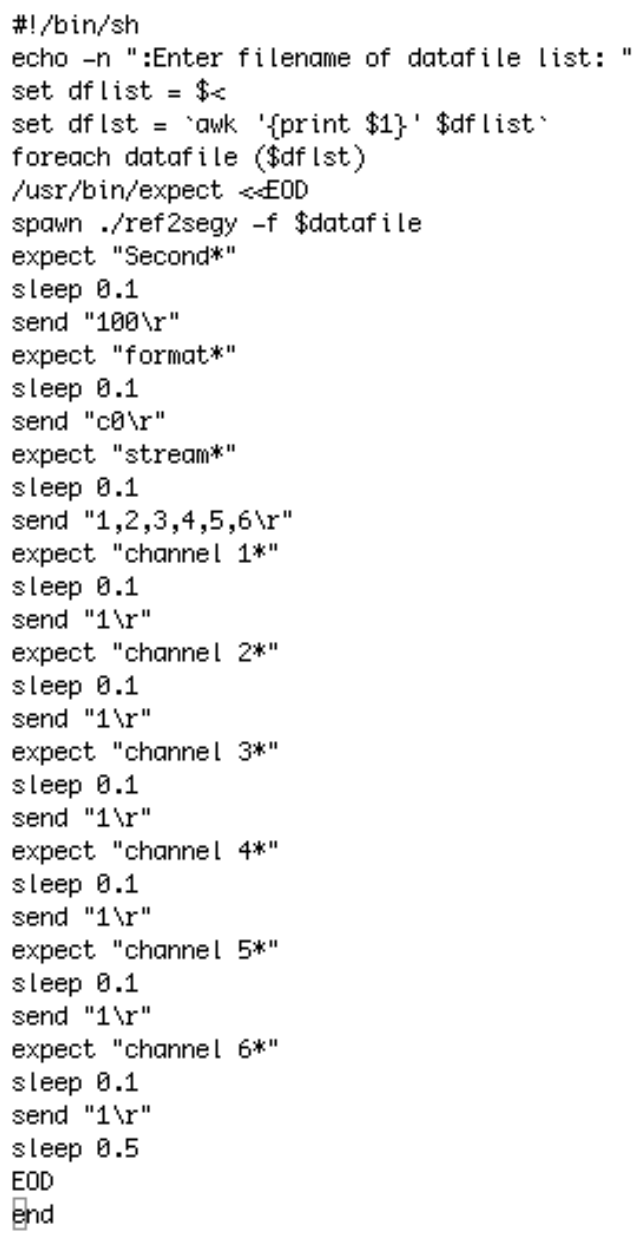

The result will be a directory like R341.01 with all the segy files, one for each channel. In that directory you then use the program segy2sac to convert segy files to SAC files. Simply type: segy2sac ** to convert all segy files to SAC. 